\title{
Frontoplastia não endoscópica, com mínimas incisões para elevação do supercílio, em portadores de paralisia facial periférica
}

\author{
Tese apresentada à Faculdade de Medicina da \\ Universidade de São Paulo para obtenção do título \\ de Doutor em Ciências \\ Programa de Otorrinolaringologia \\ Orientador: Prof. Dr. Ricardo Ferreira Bento
}



Dados Internacionais de Catalogação na Publicação (CIP)

Preparada pela Biblioteca da

Faculdade de Medicina da Universidade de São Paulo

(C) reprodução autorizada pelo autor

De Rossi, Janaína

Frontoplastia não endoscópica com mínimas incisões para elevação do supercílio em portadores de paralisia facial periférica / Janaína De Rossi. -- São Paulo, 2014.

Tese(doutorado)--Faculdade de Medicina da Universidade de São Paulo.

Programa de Otorrinolaringologia.

Orientador: Ricardo Ferreira Bento.

Descritores: 1.Paralisia facial/cirurgia 2.Ritidoplastia/reabilitação 3.Assimetria facial 4.Procedimentos cirúrgicos minimamente invasivos/método 5.Músculos faciais/cirurgia 6 .Satisfação do paciente 7 .Blefaroplastia/cirurgia 8.Pálpebras/cirurgia 9.Fotografia

USP/FM/DBD-15/14 
Pela busca da Verdade, Que a lente da ciência nos permita ver nossos erros, sem nos cegar pela razão. 


\section{AGRADECIMENTOS}

Agradeço:

Ao Prof. Dr. Ricardo Ferreira Bento, professor titular da Disciplina de Otorrinolaringologia do Hospital das Clínicas da Faculdade de Medicina da Universidade de São Paulo, figura ilustre na autoria dos livros estudados desde a graduação, que tive o prazer de conhecer e admirar durante a residência fazendo "mágicas" no centro cirúrgico... Agradeço eternamente pela oportunidade de desenvolver meu trabalho, pelo inquietante exemplo de cirurgião, professor e empreendedor no crescimento da Otorrinolaringologia no Brasil contribuindo ainda com seu reconhecimento internacional.

A Dra. Leslie Morse, médica diretora do programa de pesquisa do Spaulding Harvard SCI Model System, professora assistente da Harvard Medical School, por me receber em seu centro de pesquisa e contribuir na minha orientação com seu excelente primor científico.

A Dra. Tessa Hadlock, médica diretora do Centro do Nervo Facial do Massachussets Eye and Ear Infirmary da Harvard Medical School, por me receber em seu serviço contribuindo magnificamente com minha formação tecendo o elo entre a cirurgia plástica facial e o tratamento das sequelas de paralisia facial.

Ao Prof. Dr. Silvio A. Marone, professor titular da Disciplina de Otorrinolaringologia da Pontifícia Universidade Católica de Campinas, professor de Otorrinolaringologia da Faculdade de Medicina da Universidade de São Paulo, amigo e eterno padrinho que me iniciou pelos caminhos acadêmicos, sempre disposto e incansável trabalhador de ciência, portador de admirável sabedoria e humildade. 
Ao prof. Dr. José Carlos Marques de Faria, profa. Dra. Roseli Saraiva M. Bittar e profa. Dra. Valéria Goffi Gomes pelas primorosas contribuições que fizeram durante o exame de qualificação auxiliando definitivamente na elaboração final desta tese.

Ao Dr. José Alexandre Médicis da Silveira, médico assistente doutor da Disciplina de Otorrinolaringologia do Hospital das Clínicas da Faculdade de Medicina da Universidade de São Paulo; médico diretor da clínica Otorhinus, pela acolhida durante a residência médica, amizade, cumplicidade e educação para a vida. Nossas conversas sempre ampliaram meus horizontes e agraciaram meu Ser.

Ao Dr. Oswaldo Martucci Júnior, médico assistente da Disciplina de Otorrinolaringologia do Hospital das Clínicas da Faculdade de Medicina da Universidade de São Paulo, médico diretor da Clínica Otorhinus, amigo e eterno padrinho pelo carinho e dedicação na minha instrução durante a residência. Seu brilho iluminou minhas mais trabalhosas travessias.

Ao Dr. Mario Bernardo Guiss Rausis, foi médico assistente da Disciplina de Otorrinolaringologia do Hospital das Clínicas da Faculdade de Medicina da Universidade de São Paulo e médico diretor da Clínica Otorhinus, amigo adorado, irreverente a quem agradeço ter desfrutado da companhia e lições de residência. Que sua estrela continue brilhando onde estiver.

Ao Dr. Perboyre Sampaio, médico doutor assistente da Disciplina de Otorrinolaringologia do Hospital das Clínicas da Faculdade de Medicina da Universidade de São Paulo, criador do Grupo de Cirurgia Plástica Facial da Disciplina de Otorrinolaringologia do Hospital das Clínicas da Faculdade de Medicina da Universidade de São Paulo, pioneiro na Cirurgia Plástica Facial brasileira, por me acolher como Fellow, amiga e ainda me ensinar a operar. Obrigada por nos abrir as portas desta área de atuação e principalmente, pelo seu amor e dedicação. 
Ao Dr. Carlos Alberto Caropreso, médico assistente doutor da Disciplina de Otorrinolaringologia do Hospital das Clínicas da Faculdade de Medicina da Universidade de São Paulo, pela amizade, carinho e devoção ao ensino. Você é meu exemplo de cirurgião e ser humano.

Ao Dr. José Roberto Parisi Jurado, médico assistente da Disciplina de Otorrinolaringologia do Hospital das Clínicas da Faculdade de Medicina da Universidade de São Paulo, médico diretor do Instituto Brasileiro de Pós Graduação, pela amizade, pela sua didática exemplar e convivência prazerosa.

Ao Dr. Ronaldo Frizzarini, médico assistente doutor do Departamento de Otorrinolaringologia do Hospital das Clínicas da Faculdade de Medicina da Universidade de São Paulo, pelas valiosas contribuições no desenho e estatística deste estudo.

A Dra. Maria Cecília Lorenzi, médica pesquisadora doutora do Departamento de Otorrinolaringologia do Hospital das Clínicas da Faculdade de Medicina da Universidade de São Paulo, pela valorosa contribuição no desenho do projeto de pesquisa deste estudo.

As Dras. Carolina Passamani Fagundes, Leila Freire Rego Lima e Sandra Maytè Perez Leon, companheiras de Fellow em Cirurgia Plástica Facial, amigas irmãs além de excelentes cirurgiãs, pelo carinho, incentivo, ajuda com os atendimentos e cirurgias. Sem vocês não este trabalho certamente não existiria.

Aos funcionários do Departamento de Otorrinolaringologia do Hospital das Clínicas da Universidade de São Paulo, pelo atendimento aos pacientes, pela dedicação e contribuição com a pesquisa.

À Marileide e Lucy, por todo carinho, paciência e eficiência para me apoiarem nesta caminhada. 
Aos meus pais Dr. Sylvio De Rossi e Profa. Dra. Vera Lúcia Sabongi De Rossi por me receberem no planeta e doarem toda sua vida e seu amor para minha existência, sem cobrar nada em troca.

Às minhas irmãs Profa. Dra. Andiara De Rossi Daldegan e Dra. Moara De Rossi, companheiras de sangue e de vida, que me incentivaram e ajudaram a produzir este trabalho. Agradeço seu amor incondicional.

Ao meu marido Fernão Pompêo de Camargo, por ser a Luz da minha vida e nossa filha Gabriela acompanhando do meu ventre, a redação desta tese. 
Agradeço ainda,

Ao Conselho Nacional de Desenvolvimento Científico e Tecnológico (CNPq), pelo incentivo financeiro à pesquisa através de Bolsa de Estudos e taxa de bancada durante o curso de Pós-graduação.

Ao Centro de Estudos Avançados em Otorrinolarigologia (CEDAO), pelo apoio disponibilizando material didático e profissionais de alta qualidade. 


\section{NORMATIZAÇÃO ADOTADA:}

Esta tese está de acordo com:

Referências: adaptado de International Committee of Medical Journals Editors (Vancouver).

Universidade de São Paulo. Faculdade de Medicina. Serviço de Biblioteca e Documentação. Guia de apresentação de dissertações, teses e monografias da FMUSP. Elaborado por Anneliese Carneiro da Cunha, Maria Júlia A.L. Freddi, Maria F. Crestana, Marinalva de S. Aragão, Suely C. Cardoso, Valéria Vilhena. $3^{\text {a }}$. ed. São Paulo: Divisão de Biblioteca e Documentação; 2011.

Abreviatura dos títulos dos periódicos de acordo com List of Journals Indexed in Index Medicus. 


\section{SUMÁRIO}

Lista de abreviaturas

Lista de siglas

Lista de símbolos

Lista de figuras

Lista de gráficos

Lista de tabelas

Resumo

Abstract

1 INTRODUÇÃO

1.1 Paralisia facial periférica........................................................ 2

1.2 Supercílios........................................................................ 4

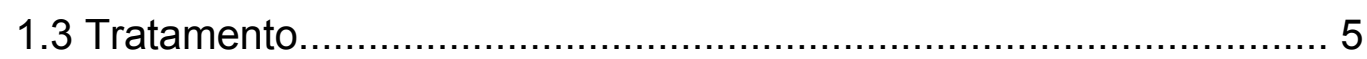

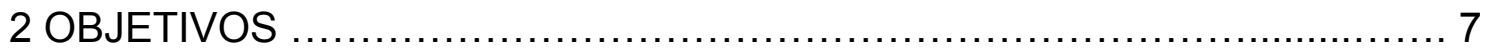

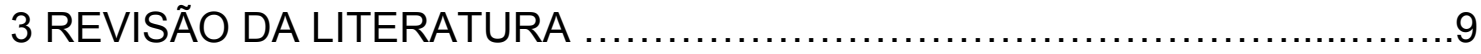

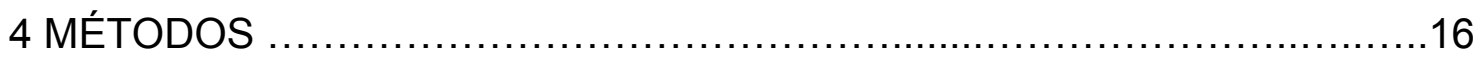

4.1 Seleção da amostra.......................................................... 17

4.1.1 Critérios de inclusão................................................17

4.1.2 Critérios de exclusão...............................................17

4.2 Métodos de avaliação..........................................................18

4.2.1 Avaliação clínica pré-operatória....................................18

4.2.2 Documentação fotográfica........................................19

4.2.3 Avaliação objetiva computadorizada.............................19

4.3 Tratamento cirúrgico......................................................... 21

4.4 Tratamento clínico...........................................................24

4.5 Avaliação objetiva pós-operatória..............................................24

4.6 Avaliação subjetiva pós-operatória.............................................24

4.7 Avaliação clínica pós-operatória..............................................25

4.8 Análise dos resultados e estatística..........................................25

4.8.1 Cálculo da amostra..............................................25 


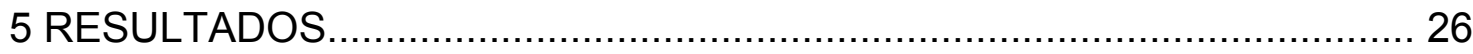

5.1 População estudada....................................................... 27

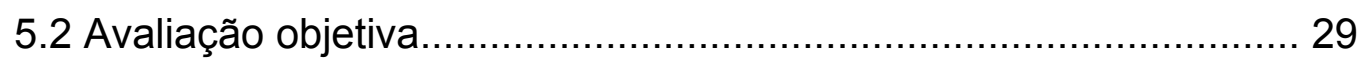

5.3 Avaliação subjetiva........................................................... 31

5.4 Avaliação clínica pós-operatória.......................................... 32

5.4.1 Complicações das cirurgias.........................................32

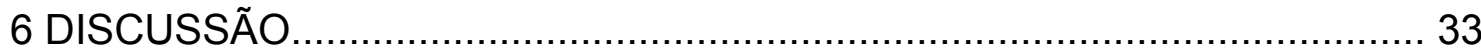

6.1 Metodologia e limitações da pesquisa.......................................34

6.2 Técnica cirúrgica.............................................................. 36

6.3 Resultado cirúrgico.................................................... 41

6.4 Considerações finais.......................................................43

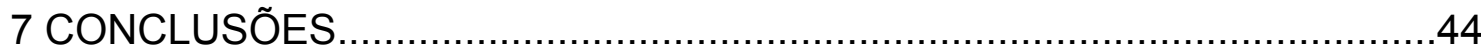

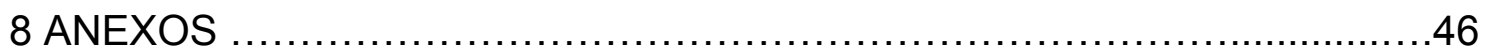

Anexo A - Protocolo de avaliação de Paralisia Facial Periférica...........47

Anexo B - Escala de House e Brackmann.....................................49

Anexo C - Escala de Sunnybrook............................................ 50

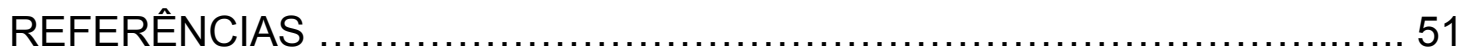

\section{APÊNDICES}

Apêndice 1 - Aprovação do projeto de pesquisa pelo comitê de ética Apêndice 2 - Aprovação de alterações do projeto de pesquisa pelo comitê de ética 


\section{LISTA DE ABREVIATURAS}

\begin{tabular}{|c|c|}
\hline Dr. & Doutor \\
\hline Dra. & Doutora \\
\hline et al. & e outros \\
\hline ed. & Edição \\
\hline p. & página \\
\hline prof. & professor \\
\hline profa. & professora \\
\hline PFP & Paralisia facial periférica \\
\hline FAF & Ferimento por arma de fogo \\
\hline HB & escala de House e Brackmann \\
\hline$d p$ & desvio padrão \\
\hline Tо & tempo zero ou tempo inicial \\
\hline T1 & primeiro intervalo de tempo \\
\hline T2 & segundo intervalo de tempo \\
\hline T3 & terceiro intervalo de tempo \\
\hline AP & linha do canto lateral da hemiface paralisada \\
\hline BP & linha do centro da pupila da hemiface paralisada \\
\hline CP & linha do canto medial da hemiface paralisada \\
\hline AC & linha do canto lateral da hemiface contralateral \\
\hline BC & linha do centro da pupila da hemiface contralateral \\
\hline CC & linha do canto medial da hemiface contralateral \\
\hline
\end{tabular}




\section{LISTA DE SIGLAS}

CAPPesq Comissão de ética para análise de projetos de pesquisa

FMUSP Faculdade de Medicina da Universidade de São Paulo

HC Hospital das Clínicas

USP Universidade de São Paulo

SUS Sistema Único de Saúde 


\title{
LISTA DE SÍMBOLOS
}

\author{
cm centímetro \\ mm milímetro \\ $\%$ porcento \\ $\pm \quad$ mais ou menos \\ ® marca registrada \\ $=\quad$ igual $\mathrm{a}$ \\ $<\quad$ menor que \\ $>\quad$ maior que \\ $\leq \quad$ menor ou igual a \\ $\geq \quad$ maior ou igual a
}




\section{LISTA DE FIGURAS}

Figura 1 Software desenvolvido para medir nas fotos as linhas determinadas pelo usuário 20

Figura 2 Linhas verticais determinadas a partir dos pontos de referência até 0 limite superior dos supercílios 20

Figura 3 Dissecção do retalho na porção frontal, através da incisão temporal. 23

Figura 4 Identificação da Linha Temporal após a dissecção das porções temporal e frontal do retalho. A secção da linha temporal vai unir as duas porções criando um retalho único. 23

Figura 5 Dissecção do retalho na região do Arcus marginalis, e liberação do mesmo raspando o periósteo do rebordo orbitário superior e lateral .23

Figura 6 Agulha de Reverdin utilizada para passagem do fio sob o retalho, fazendo ancoragem no tecido subcutâneo na altura da cabeça do supercílio, com posterior fixação na altura da incisão no couro cabeludo. 


\section{LISTA DE GRÁFICOS}

Gráfico 1 Fluxograma do número de indivíduos incluídos na casuística e quantos compareceram em cada intervalo de avaliação pós-operatória.

Gráfico 2 Médias da posição dos 2 supercílios no pré- operatório, em todas as linhas, em milímetros. .28

Gráfico 3 Comparação das medidas dos supercílios em todas as linhas, em todos os intervalos, em milímetros 31

Gráfico 4 Grau de satisfação dos indivíduos com a cirurgia.32 


\section{LISTA DE TABELAS}

Tabela 1 Caracterização da população estudada, avaliação clínica das sequelas da PFP 18

Tabela 2 Medidas verticais dos pontos de referência ao limite superior dos supercílios no início do estudo (T0), em milímetros........21

Tabela 3 Intervalos de avaliação dos pacientes. .24

Tabela 4 Características da população acompanhada aos 24 meses após a cirurgia .28

Tabela 5 Comparação das medidas, em milímetros, obtidas na linha AP entre T0 e T2.

Tabela 6 Comparação das medidas obtidas na linha AP em 15 indivíduos entre pré e 24 meses pós-operatório, segundo a intenção de tratar, pelo "pior cenário" ( $\mathrm{T} 2=$ T0) .29

Tabela 7 Comparação das medidas obtidas na linha AP entre pré e 24 meses pós-operatório, completando os faltantes com as médias obtidas entre T1 e T3, segundo a intenção de tratar. 30

Tabela 8 Médias das medidas na linha AP em T0, T1 e T3 .30 


\section{RESUMO}

De Rossi J. Frontoplastia não endoscópica com mínimas incisões para elevação do supercílio, em portadores de paralisia facial periférica [tese]. São Paulo: Faculdade de Medicina, Universidade de São Paulo; 2014.

Novas técnicas de frontoplastia, assistidas ou não de endoscópio, têm sido utilizadas na tentativa de diminuir as incisões tradicionalmente bi-coronais. Contudo, os resultados das cirurgias realizadas com mínimas incisões, sem endoscópio, ainda não são bem conhecidos, principalmente quando há sequelas de paralisia facial periférica (PFP). Dessa forma, o objetivo do presente estudo prospectivo foi avaliar a eficácia da frontoplastia não endoscópica com mínimas incisões na elevação do supercílio em indivíduos com PFP, 24 meses após a cirurgia. Constituíram variáveis do estudo a posição dos supercílios aferida em milímetros em fotografias digitais, por um software especialmente criado para este fim. Exploratoriamente, as fotos foram também avaliadas após o intervalo de 12 meses, e ainda, entre 36 a 78 meses. A satisfação dos pacientes com o resultado cirúrgico foi questionada verbalmente com a utilização de duas perguntas. A primeira, se o paciente estava satisfeito ou não e; a segunda, como o paciente qualificava sua aparência pós-cirurgia (entre as opções: pior, indiferente, melhor ou muito melhor). A amostra foi composta por 20 pacientes adultos que sofreram PFP há mais de 12 meses, com paralisia residual do ramo temporal e ptose do supercílio. Os pacientes foram submetidos a frontoplastia através de 2 incisões temporais no couro cabeludo, medindo $2,5 \mathrm{~cm}$ cada. Quando desejada fixação da parte medial do supercílio, esta foi realizada com agulha de Reverdin e 1 ou 2 incisões frontais acessórias, de $1 \mathrm{~cm}$ cada no couro cabeludo. Foi realizado descolamento frontal e temporal pelo plano subgaleal e liberação dos ligamentos do arcus marginalis sem visualização direta, com palpação externa dos reparos anatômicos. Não ocorreram lesões neurais sensitivas ou motoras permanentes em nenhum paciente em decorrência deste procedimento. As medidas pós-operatórias dos supercílios foram maiores do que as préoperatórias $(p<0,05)$ mostrando a eficácia da cirurgia na elevação do supercílio pós PFP após 24 meses. Todos os pacientes ficaram satisfeitos e qualificaram sua aparência como "melhor" ou "muito melhor".

Descritores: Paralisia facial/cirurgia, Ritidoplastia/reabilitação, Assimetria facial, Procedimentos cirúrgicos minimamente invasivos/métodos, Músculos faciais/cirurgia, Satisfação do paciente, Blefaroplastia/cirurgia, Pálpebras/cirurgia, Fotografia. 


\section{ABSTRACT}

De Rossi J. Nonendoscopic minimal incision Forehead lift for brow suspension in peripheral facial paralysis subjects [thesis] São Paulo: "Faculdade de Medicina, Universidade de São Paulo"; 2014.

New forehead lift techniques assisted by endoscopic visualization or not, have currently been used to reduce the traditional bi-coronal incision. However, the results of surgeries performed with minimal incisions are unknown, especially when given in cases of sequelae of peripheral facial paralysis (PFP). Therefore, the objective of this prospective study was to assess the efficacy of nonendoscopic forehead lift with minimal incisions in PFP patient brow suspension, 24 months after surgery. Study variables were the position of the eyebrow assessed in millimeters on digital photographs, by software developed for this purpose. Brow position after 12 month and also between 36 and 78 months was exploratory analyzed. Patient's satisfaction and improvement was verbally inquired after surgery "are you satisfied or not" and "are you looking worst, the same, better or much better". The sample was composed of 20 adult patients who suffered PFP over 12 month and remain with paralysis of the temporal branch and eyebrow ptosis. Patients underwent forehead lift performed by two incisions in the lateral hair bearing area measuring $2.5 \mathrm{~cm}$ each. When desired medial eyebrow fixation a Reverdin needle was used and an extra incision measuring $1 \mathrm{~cm}$ each was placed centrally on hair bearing. Frontal and temporal flap detachment was performed by subgaleal plane and the release of the arcus marginalis was blindly accomplished by external palpation, minding anatomic parameters. No patient exhibited permanent sensitive or motor neural lesion after this procedure. Eyebrow position in the post-operative periods was higher than pre-operative $(p<0,05)$ confirming brow lift efficacy 24 months after surgery. Al the patients declared satisfied and qualified themselves as looking "better" or "much better".

Descriptors: Facial paralysis/surgery, Rhitidoplasty/rehabilitation, Facial asymmetry, Surgical procedures, minimally invasive/methods, Facial muscle/surgery, Patient satisfaction, Blepharoplasty/surgery, Eyelids/surgery, Photography. 
1. INTRODUÇÃO 


\section{INTRODUÇÃO}

\subsection{Paralisia facial periférica}

O nervo facial, o sétimo dos pares cranianos, origina-se no núcleo do facial localizado na ponte e emerge pelo sulco bulbo pontino, próximo ao cerebelo. Faz tortuoso trajeto pelo osso temporal e emerge do crânio pelo forame estilomastoideo. Suas fibras são predominantemente motoras, exceto pela raiz sensitiva e visceral do nervo intermédio (de Wrisberg); responsável pela gustação dos dois terços anteriores da língua e inervação pré ganglionar das glândulas lacrimal, submandibular e sublingual. Na porção intratemporal emite ramo para o músculo estapédio. No segmento extra craniano se divide em ramos motores que atravessam a glândula parótida e se distribuem para os músculos mímicos, etilo-hioideo e ventre posterior do digástrico (Machado, 2002).

Afecções deste nervo causam paralisia facial periférica (PFP) pela perda das funções motoras, e não motoras, que causam alterações no paladar, lacrimejamento, sensibilidade auditiva e gustação. A desenervação dos músculos da mímica, além da dificuldade de expressão das emoções e alterações estéticas prontamente notáveis, pode comprometer a oclusão palpebral reduzindo a proteção ocular natural. A abertura excessiva e contínua pode ocasionar dor, irritação, fotofobia, intolerância ao vento, lacrimejamento e alteração estética. O comprometimento do nervo corda do tímpano reduz o paladar; a incompetência dos músculos periorais prejudicam a articulação de algumas sílabas e a continência do bolo alimentar na cavidade oral, dificultando também a limpeza dos, sulcos gengivais durante alimentação; a mastigação seletiva pode desequilibrar a oclusão dental e articulações têmporomandibulares provocando dor e desgastes (De Rossi et al., 2011).

Existem diversas causas que desencadeiam PFP sendo predominantes as de características inflamatórias e idiopáticas. Nestes casos, o tratamento pode incluir uso de antiinflamatório hormonal, antiviral e profilaxia das complicações oculares. As lesões traumáticas e iatrogênicas devem ser reparadas precocemente e o tratamento cirúrgico de tumores junto ao nervo 
facial deve sempre considerar a integridade deste. Pacientes que tenham evolução desfavorável, detectados precocemente pelos testes eletrofisiológicos, podem se beneficiar da descompressão intratemporal do Nervo (Bento et al., 2013).

A Paralisia facial periférica afeta 24 a 40 em 100 mil habitantes (Peitersen 2002; Ushio 2008; de Almeida et al. 2009; Monini et al. 2010). A Paralisia de Bell é a causa mais comum de PFP nas maiores séries de casos. Caracterizase por início súbito, dor retroauricular e tem evolução benigna, notadamente nos indivíduos menores de 60 anos com presença de reflexo estapediano e lacrimejamento normal. Se após 6 meses não houver melhora dos sintomas deve ser feita investigação para afastar a etiologia tumoral (Hoffman, 1992).

Em cerca de 30\% dos casos (Hydén 1982; Peitersen 2002), os indivíduos não se recuperam completamente após 12 meses e são considerados como portadores de seqüelas. A localização, intensidade e característica das disfunções são diversas. No convívio social a aparência e a expressão facial dos indivíduos são parte da comunicação humana. Diante da existência de deformidades faciais, estes indivíduos, na maioria das vezes, sofrem alterações psíquicas que podem comprometer seu comportamento social (Miniti et al., 2000).

Nas paralisias do músculo frontal, responsável pela elevação do supercílio, ocorre ptose notadamente na porção lateral do rebordo supra orbitário, onde não há firme aderência do tecido mole (Lemke e Stasior, 1982). A assimetria prejudica a aparência, comunicação não verbal e expressão emocional (Rautio e Pignatti, 2001; Sadr et al., 2003). Esses pacientes podem sentir peso sobre o olho, conjuntivite recorrente, ulceração de córnea e redução de campo visual, de acordo com o grau de ptose. Somado à paralisia do músculo frontal de uma hemiface, o músculo contralateral torna-se mais ativo para compensar, acentuando a assimetria. A posição assimétrica do supercílio pode estar presente também em repouso e tornar-se mais evidente, após a correção dos terços médio e inferior da face, por outros procedimentos (Clark e Schockley, 2002). 


\subsection{Supercílio}

Segundo estudo antropométrico (Whitaker et al., 1986) o supercílio é uma parte importante das estruturas do rebordo supra orbital. Apesar de sua configuração e contorno serem dependentes da estrutura óssea, a manipulação de partes moles pode alterá-lo. Em relação ao rebordo orbitário o supercílio começa medialmente justa-inferior, situa-se no rebordo propriamente dito em seu terço médio e termina lateralmente justa-superior ao mesmo. $\mathrm{O}$ ponto mais alto do supercílio fica na transição do terço médio para o lateral e recebe a denominação de supraciliare. Esta supra inclinação é considerada pela sociedade, como padrão de embelezamento recebendo maquiagem, ou remoção de pelos para acentuá-la.

A altura dos supercílios sofre alteração com o envelhecimento, ação gravitacional e muscular facial e se espera ptose natural no decorrer dos anos (Isse, 1994; Ramirez, 1994). Entretanto a posição do supercílio foi aferida por Matros et al. em 2009, em grupos de indivíduos de 20 a 30 anos e comparado ao grupo de 50 a 60 anos e as medidas foram maiores no grupo senil, sugerindo elevação com o envelhecimento. A posição ideal do supercílio é controversa, mas existe uma tendência de suspensão deste entre os cirurgiões que almejam rejuvenescimento ou embelezamento facial (Freund e Nolan, 1996; Gunter e Antrobus, 1997).

Sadr et al. em 2003 testaram o papel do supercílio no reconhecimento dos indivíduos. Utilizando fotografias de 50 faces famosas modificadas com Adobe Photoshop $®$ criaram 2 grupos, um de 25 artistas sem os supercílios e o outro de 25 artistas sem os olhos. As fotos alteradas foram exibidas para 18 voluntários. Na segunda etapa mostraram também as 50 fotos originais. Em cada uma das 100 fotos exibidas, os voluntários apertavam um botão assim que reconhecessem a pessoa e depois a descreviam. Notaram que o reconhecimento do grupo sem supercílio foi menor que o grupo sem os olhos. Consideraram que os resultados sugerem que o supercílio tem importante papel no reconhecimento da face do indivíduo. 


\subsection{Tratamento}

Atualmente quase todos os indivíduos com seqüela de paralisia facial podem apresentar melhora após a realização procedimentos cirúrgicos reabilitadores. Estes procedimentos visam obter aparência normal em repouso; simetria durante a mímica facial; restabelecimento do controle dos esfíncteres bucal, nasal e ocular; simetria durante movimentos reflexos e expressões da face. Dentre as cirurgias possíveis, verifica-se a preferência pelas reconstruções dinâmicas às estáticas (Hoffman, 1992; Parnes e Batniji, 2001; Hadlock, 2008).

Entretanto os procedimentos atualmente disponíveis para re-enervação (como transferência neural) não mostram resultados satisfatórios para região frontal (Sobol e May,1991; Stennert E, 1994; De Rossi et al., 2011) e a maioria dos autores concorda que a combinação de procedimentos como aplicação de toxina botulínica e cirurgias de suspensão estática favorecem o resultado final e prognóstico (Freeman, 1979; Gulane e Cheng, 1991; Parnes e Batniji, 2001; Clark e Shockley, 2002; Hadlock et al., 2006; De Rossi et al. 2011).

A suspensão estática dos supercílios em pacientes com sequela de paralisia no músculo frontal pode ser feita pela frontoplastia coronal, porém requer incisão extensa no couro cabeludo e não é bem aceita pelos pacientes. Além disso, foram descritos resultados estéticos insatisfatórios devido à elevação exagerada dos supercílios, disestesia permanente na região frontoparietal, distriquia e até alopecia na região da incisão (Troilius, 1999; Dayan et al., 2001; Seify et al., 2004). Outra possibilidade, conhecida como frontoplastia direta, retira um fuso de pele e tecido subcutâneo junto à margem superciliar superior ou ruga frontal e sutura as margens obtendo elevação do supercílio; o aspecto negativo é a cicatriz visível.

$\mathrm{Na}$ medicina atual, o uso do endoscópio possibilita a diminuição das incisões e torna algumas cirurgias minimamente invasivas. A frontoplastia endoscópica ganhou grande popularidade devido a menores incisões, redução de edema pós-operatório, incidência de alopecia e hipoestesias prolongadas de escalpo possibilitando reabilitação mais rápida (Troilius, 1999; Dayan et al., 
2001; Takushima et al., 2003; Seify et al., 2004). Contudo, a necessidade de equipamentos e treinamento específicos tornam este procedimento oneroso.

Semelhante à frontoplastia endoscópica, o procedimento pode ser realizado através de pequenas incisões, sem a necessidade do endoscópio (Knize, 1996; Kikkawa et al., 2000; Tabatai e Spinelli, 2007; Marten, 2008). O descolamento do retalho frontal e liberação dos ligamentos são cuidadosamente orientados pelo plano cirúrgico evitando lesões a vasos e nervos. Os feixes vásculonervosos são identificados anatomicamente por palpação e protegidos de lesões durante estas etapas. O retalho liberado é suspenso até a posição desejada e fixado. A frontoplastia não endoscópica, por mínimas incisões torna o procedimento minimamente invasivo, mais rápido e dispensa equipamentos e treinamento especializados, podendo ser realizado em pacientes com PFP (Constantino et al., 2003).

Diante da escassez de estudos prospectivos, com medidas consistentes pós frontoplastia não endoscópica, idealizamos este estudo para técnica com mínimas incisões em ptose de supercílio decorrente de seqüela de PFP. A hipótese inicial é a de que tal técnica é eficaz para suspensão estática do supercílio e o resultado é capaz de satisfazer o paciente com PFP. 
2. OBJETIVOS 


\section{OBJETIVOS}

O objetivo principal do presente estudo foi avaliar o efeito da frontoplastia não endoscópica, com mínimas incisões na elevação do supercílio de indivíduos com seqüela de paralisia facial periférica, através de medidas computadorizadas realizadas nas fotos antes e 24 meses após a cirurgia. $O$ ponto de elevação selecionado para aferição foi na linha vertical traçada do canto palpebral lateral ao supercílio na hemiface paralisada.

Os objetivos secundários foram avaliar o grau de satisfação dos indivíduos com o resultado da frontoplastia não endoscópica com mínimas incisões, 24 meses após a cirurgia e exploratoriamente medir a posição dos supercílios, após 12 e entre 36 a 78 meses. 
3. REVISÃO DE LITERATURA 


\section{REVISÃO DE LITERATURA}

Para Burgess e Goode (1994) os procedimentos corretivos para paciente com paralisia facial periférica podem ser classificados como estáticos ou dinâmicos. Dinâmicos têm a intenção de promover movimento facial ativo e geralmente são preferidos. Entretanto, estes procedimentos podem causar danos na área doadora e podem ser menos indicados para defeitos localizados. Procedimentos estáticos não promovem movimentação ativa, porém são úteis para obter simetria em repouso e podem ser utilizados como adjuvante aos procedimentos dinâmicos.

Stennert E, (1994) acompanhou 55 pacientes (com idade variando de 6 a 65 anos) que sofreram secção completa do nervo facial na região do ouvido, corrigida com enxerto de nervo grande auricular. Após seguimento de 12 meses o autor observou - com eletromiografia de agulha - que havia sinal de reinervação do músculo frontal em todos os pacientes, mas 42 pacientes (77\%), não eram capazes de elevar o supercílio na hemiface comprometida. A hipótese deste autor foi a de que o desequilíbrio resultante entre os vetores de ação muscular frontal (elevação) e músculos depressores do supercílio com recuperação aberrante, favorecem a ação muscular depressora impedindo a elevação do supercílio.

De acordo com May et al. (2000), a frontoplastia para elevação do supercílio em PFP pode ser via direta por incisão na margem superior do supercílio, no meio da fronte ou coronal. Estes autores descrevem a via direta com ressecção cutânea sobre o limite superior do supercílio, sutura com nylon 4.0 fixando a margem inferior da incisão ao periósteo frontal (2 ou 3 pontos), elevando o supercílio e utilizando sutura delicada para fechamento da pele. Como complicação citam a cicatriz visível e elevação excessiva. Relatam também sucesso na elevação do supercílio via endoscópica em 12 pacientes, com a vantagem das cicatrizes ficarem ocultas no couro cabeludo. Consideraram, como desvantagens, o custo da técnica devido à utilização de material especializado e desconhecimento dos resultados em longo prazo.

Ueda et al. (1994), publicaram uma revisão de 40 indivíduos com ptose de supercílio, pós PFP, operados pela excisão direta de pele sobre o supercílio após 3 até 10 anos. Todos apresentavam paralisia completa ou quase 
completa dos músculos frontal e orbicular. A avaliação foi feita nas fotos pré e pós-operatórias e na avaliação do paciente, determinando se o supercílio estava simétrico, mais alto ou mais abaixo, em relação ao contralateral. Avaliaram também o campo visual, a sensibilidade da fronte e as condições da cicatriz. Observaram que $65 \%$ dos pacientes estavam com o supercílio simétrico, $7,5 \%$ acima e $27,5 \%$ abaixo e correlacionaram este achado com o status pré operatório, concluindo que os casos mais severos apresentaram recorrência, mesmo após a cirurgia ter sido repetida nestes indivíduos. Notaram tambem que a recidiva começou a partir de 1 ano, mas não houve queda adicional nos demais anos. O número de pacientes em que o supercílio ficou acima do contralateral foi menor após 1 ano. Oitenta e cinco por cento melhoraram o campo visual e 11 indivíduos se queixaram de perda de sensibilidade frontal. Consideraram a cicatriz boa em $77,5 \%$ e ruim em $22,5 \%$.

Em artigo sobre as abordagens do supercílio pós PFP Meltzer e Byrne (2008) dividiram os procedimentos em diretos (com incisão na margem superciliar, seguindo alguma ruga frontal ou coronal) ou endoscópicos. Entre as vantagens dos procedimentos diretos estão a facilidade técnica $\mathrm{e}$ previsibilidade do resultado, a desvantagem é a cicatriz. Por outro lado a técnica endoscópica minimiza os efeitos colaterais e cicatrizes das técnicas diretas. As desvantagens são maior tempo cirúrgico, custo de treinamento e uso de equipamentos especializados.

Rubin (1991) descreve uma técnica de suspensão adicional com um "tendão de fáscia frontalis temporalis". Além da suspensão coronal realizada na frontoplastia, o autor confecciona uma fita de músculo frontal de $2 \mathrm{~cm}$, do lado não paralisado da fronte, pediculada superiormente ao Músculo. Realiza um prolongamento desta com fáscia temporal e faz a suspensão da cabeça do supercílio paralisado. Assim favorece a elevação da parte medial do supercílio com o movimento do músculo frontal contralateral.

Desde sua descrição inicial por Vasconez et al. (1992) ${ }^{1}$, (appud Ramirez, 1994), a frontoplastia endoscópica ganhou grande popularidade no rejuvenescimento do terço superior da face. As vantagens são: menores incisões, menor edema pós-operatório, menor incidência de alopecia e hipoestesias prolongadas de escalpo e reabilitação mais rápida.

\footnotetext{
${ }^{1}$ annual meeting of American society of plastic and reconstructive surgeons. Washington, 1992.
} 
A frontoplastia endoscópica foi denominada como "funcional" por Isse em 1994 pois a criação de retalho único, aliada a liberação dos ligamentos do arcus marginalis e ressecção parcial dos músculos depressores do supercílio favorece a ação da musculatura responsável pela elevação.

Knize, em 1996 e 1999, descreveu a frontoplastia com incisões limitadas baseada em dissecções de cadáveres para elevação de supercílio de qualquer grau. Realizada por até 4 incisões no escalpo de 4,5 a $5 \mathrm{~cm}$, combinada a incisão na pálpebra superior para tratamento da musculatura glabelar, obteve resultado que considerou comparável ao obtido pela frontoplastia coronal no seguimento de 140 indivíduos operados por razões estéticas. Fez elevação do retalho frontal via subperiosteal e retalho temporal pelo plano subgaleal, enfatizando que o plano de dissecção sobre a fáscia temporal assegura a integridade do ramo temporal do nervo facial. A linha temporal é seccionada com tesoura até o nível do rebordo orbitário superior, seguida pela liberação da inserção da gálea aponeurótica que deve ser cuidadosa, sob visualização direta com auxílio de foco de luz frontal e instrumento rombo minimizando o risco de lesão ao nervo supraorbitário. Segue verticalmente com a dissecção até o terço anterior do arco zigomático. Nesta região o nervo facial está junto da fáscia, enquanto que mais lateralmente está mais fixo, junto ao periósteo. Eleva o retalho e faz uma "janela" retirando a fáscia temporal no local onde pretende fixar o retalho para melhorar a aderência e sutura o retalho no músculo com Vicryl 2.0. Em 1999 o autor publicou a técnica após operar com sucesso mais de 450 pessoas, acompanhadas por mais de 5 anos e meio.

Em estudo retrospectivo Tabatabai e Spinelli (2007) compararam a frontoplastia endoscópica realizada em 100 pacientes com finalidade estética, de 1999 a 2004, com 93 submetidos a mesma técnica cirúrgica de 2002 a 2005, porém sem a visualização endoscópica. Realizaram descolamento subperiosteal em direção anterior pela fronte até o rebordo orbitário superior e lateral e posteriormente até o vertex. Fixaram o retalho usando métodos variados. Observaram resultados satisfatórios, duráveis e poucas complicações nos dois grupos de pacientes, acompanhados no pós-operatório de 6 meses a 5 anos. $O$ tempo transoperatório médio foi menor no grupo da cirurgia não endoscópica, o tamanho das incisões também foi menor neste grupo. 
Concluem que a técnica não endoscópica é segura, mais rápida e o custo menor quando comparada a endoscópica.

As estratégias de fixação do retalho são diversas e incluem confecção de túnel no osso da calota craniana, colocação de parafusos, placas e suturas com material permanente ou temporário (absorvível). Kennedy e Pogue (1999) indicaram o uso de parafusos para elevações superiores a 0,5 cm. A fixação da região temporal tem pouca variação, normalmente é feita com sutura sobre o músculo temporal.

Troillius (2004) publicou uma série de casos de frontoplastia endoscópica subperiostal e observou que de 1 a 5 anos pós cirurgia o supercílio se eleva (em média $2,5 \mathrm{~mm}$ ) concluindo que para suspensão de até $4 \mathrm{~mm}$, com resultado natural, não é necessária fixação do retalho. Neste mesmo estudo observou que o grupo de pacientes submetidos a blefaroplastia superior concomitante não apresentou queda do supercílio comparado ao grupo que realizou apenas frontoplastia.

Rautio e Pignatti (2001) descrevem uma série de 12 pacientes com ptose de supercílio pós PFP submetidos a frontoplastia endoscópica. A técnica foi realizada com 2 incisões acima da linha dos cabelos e a dissecção seguiu plano subperiostal na região central e sobre a fáscia intermediária lateralmente com união destes planos e liberação dos ligamentos na margem orbitária superior sob visualização endoscópica. Ressecaram os músculos corrugador e prócerus e fixaram o retalho com fios de ácido polilático de longa duração fixados a 2 parafusos absorvíveis, também de ácido polilático na calota craniana. As cirurgias foram sob anestesia geral e não realizaram blefaroplastia concomitante para evitar lagoftalmo. O acompanhamento pós operatório foi realizado entre 9 e 37 meses e compararam a ptose existente nas fotos pré operatórias classificando em leve, moderada ou severa. A posição do supercílio no lado com paralisia facial foi comparado ao lado sadio e classificada em mais alta, igual ou inferior. Em 7 pessoas a posição do supercílio paralisado estava igual ao contralateral, em 3 estava abaixo (2 estavam mais alto no seguimento mais recente e desceram a longo prazo) e em 2 estava mais alto no pós operatório. Como complicações relatam 1 caso de sangramento na glabela que ao ser cauterizado provocou queimadura que precisou de flap glabelar. Um caso reclamou de dor e sensação de aperto, foi removido o parafuso porém a 
sensação persistiu de forma intermitente até o $28^{\circ}$ mês. Todos os pacientes apresentaram parestesia frontal que durou vários meses e vários apresentaram desconforto muito significativo nos primeiros dias após a cirurgia.

Takushima et al. (2003) realizaram frontoplastia endoscópica unilateral (no lado paralisado da fronte) para correção da assimetria dos supercílios pós PFP em 51 pacientes. Seguiram o plano de dissecção subperiosteal e realizaram fixação do retalho à calota craniana utilizando parafusos. Compararam os pacientes por grupos de idade e identificaram maior assimetria no grupo de maior idade. Após seguimento de 1 ano, encontraram mais recorrência da assimetria nos pacientes mais idosos. Correlacionam a maior idade com menor sucesso na cirurgia.

Ducic e Adelson (2005) acompanharam 31 pacientes por no mínimo 1 ano após a cirurgia e realizaram comparação entre a assimetria dos supercílios antes e após a frontoplastia endoscópica. Encontraram redução em milímetros na diferença entre os supercílio antes e após a cirurgia. O método de aferição do resultado foi através de medidas realizadas pelos próprios autores nas fotos pré e pós-operatórias e de telefonemas para inquirir a satisfação dos pacientes após a cirurgia.

Ampliando as possibilidade desta cirurgia Moody et al. (2001) relataram 3 casos onde foi combinada elevação endoscópica do supercílio e neurectomia do ramo temporal contralateral e miotomia do corrugador com resultados satisfatórios no equilíbrio da fronte.

A elevação do supercílio minimamente invasiva ("Minimally Invasive Brow suspension") foi descrita para melhora da assimetria entre os supercílios em paralisia facial (Constantino et al., 2003). Por este autor foi realizada seletivamente na hemiface paralisada; com 3 incisões no supercílio (na cabeça, corpo e cauda) e 3 incisões frontais (no couro cabeludo medindo de 5 a $8 \mathrm{~mm}$ cada) seguindo esta mesma direção. Descolamento subperiosteal, às cegas, do couro cabeludo ao rebordo orbitário com palpação da região supra-orbitária na origem dos vasos e nervos, evitando lesão. Passagem de fios de nylon pelo músculo frontal com instrumento usado em cirurgia ortopédica e laparoscópica (Hewson suture retriever) elevando o supercílio e fixando a sutura ao pericrânio. Os autores avaliaram subjetivamente o resultado nas fotos após 1 ano, comparando a posição do supercílio operado com o não operado. 
Concluiram que a técnica é simples, eficiente e durável, além de dispensar o treinamento e o material necessários para frontoplastia endoscópica.

Kikawa et al. (2000), descreveram uma técnica semelhante a utilizada na frontoplastia endoscópica, porém sem auxílio do endoscópio. Realizaram 4 incisões de $2 \mathrm{~cm}$ cada, localizadas a $2 \mathrm{~cm}$ da linha triquial, sendo 2 frontais e 2 temporais. Realizaram descolamento do retalho frontal subperiosteal e temporal subgaleal com união dos planos. A região supra-orbitária foi visualizada pela incisão da blefaroplastia superior e por esta via os ligamentos supra-orbitários foram descolados completando a liberação do retalho. Se necessário, realizavam também miotomias por este acesso. Fixaram o retalho ao osso frontal com parafusos de titânio. Avaliaram as fotos pré e pósoperatórias medindo em $\mathrm{mm}$ a distancia do centro da pupila ao supercílio e os autores graduaram o resultado como bom regular ou pobre durante seguimento pós-operatório de 17 meses em média. Todos os pacientes apresentaram elevação do supercílio esteticamente gratificante e melhora das rugas frontais, em relação as complicações houve 1 caso de equimose glabelar por tempo prolongado e 1 caso de excesso residual de pele na pálpebra superior. Nenhum paciente apresentou paralisia facial ou alteração sensitiva na região.

Yamamoto et al. (2001) descreveram uma técnica de frontoplastia unilateral para ptose de supercílio pós PFP. Utilizaram 3 incisões de $1 \mathrm{~cm}$ no couro cabeludo na direção da cabeça, corpo e cauda do supercílio. Realizaram descolamento do retalho através destas incisões até o rebordo orbitário e posteriormente utilizaram o endoscópio para visualizar os nervos supraorbital e supratroclear. Utilizaram um instrumento (Mitek Tacit $囚$ ) para ancorar 3 fios de sutura ao tecido subcutâneo da cabeça, corpo e cauda do supercílio, fixando superiormente em um túnel ósseo. Acompanharam 3 indivíduos operados por esta técnica por 18 meses relatando eficiência e ausência de complicações.

Em uma revisão sistemática da literatura, comparando frontoplastia aberta e endoscópica para rejuvenescimento (Graham et al., 2011) não foi encontrado nenhum estudo prospectivo randomizado controlado no período de 1992 a 2010. Os autores selecionaram 15 análises retrospectivas e prospectivas e concluíram que faltam estudos consistentes enfatizando a padronização de medidas na evolução após a cirurgia, seguindo o princípio da medicina baseada em evidências. 
4. MÉTODOS 


\section{MÉTODOS}

O presente estudo prospectivo, não randomizado, sendo indivíduo seu próprio controle foi aprovado pela Comissão de Ética para Análise de Projetos de Pesquisa (CAPPesq) da diretoria do Hospital das Clínicas da Faculdade de Medicina da Universidade de São Paulo (HCFMUSP) (protocolo de pesquisa ${ }^{\circ}$ 933-05 - Apêndices 1 e 2).

\subsection{Seleção da amostra}

A amostra de conveniência foi composta por 20 pacientes adultos, 4 homens e 16 mulheres com idade variando de 27 a 68 anos (mediana 58), que apresentaram paralisia facial periférica (PFP) e foram acompanhados no grupo de Paralisia Facial do ambulatório de Otorrinolaringologia do Hospital das Clínicas (HC) da Faculdade de Medicina da Universidade de São Paulo (USP). O diagnóstico foi baseado nos critérios adotados pelo mesmo ambulatório (anexo A). O tempo decorrido desde a instalação da PFP até o início do estudo variou de 12 a 168 meses (mediana 19 meses).

4.1.1 Critérios de inclusão:

- Indivíduos adultos

- Paralisia facial periférica há mais de 12 meses, mantendo deficiência na contração do músculo frontal

- Ptose sintomática (estética ou funcional) do supercílio

4.1.2 Critérios de exclusão:

- Contra indicação anestésica ou cirúrgica

- Aplicação de toxina botulínica há menos de 4 meses da cirurgia ou da documentação fotográfica

- Ptose acentuada do supercílio (medida menor ou igual a $12 \mathrm{~mm}$ nas linhas verticais obtidas em 4.2.3 Avaliação objetiva computadorizada) 


\subsection{Métodos de Avaliação}

\subsubsection{Avaliação clínica pré-operatória}

O grau de PFP foi estabelecido de acordo com a escala de House e Brackmann (anexo B). A posição dos supercílios foi observada com a musculatura facial em repouso, pela inspeção e palpação do rebordo orbitário superior. Foi considerado com ptose o supercílio localizado inferiormente ao rebordo orbitário superior. A presença de sincinesia foi determinada clinicamente pela observação de contração muscular involuntária, desencadeada pela mímica facial. A quantificação da sincinesia e ação do músculo frontal foram baseados na escala facial de Sunnybrook (anexo C) e encontram-se na tabela 1. A sensibilidade da fronte foi testada com o paciente de olhos fechados, tocando a pele com algodão nas duas metades da face.

Tabela - 1 Caracterização da população estudada, avaliação clínica das sequelas da PFP

\begin{tabular}{|l|l|l|l|l|}
\hline Etiologia da PFP & Grau de PFP & Grau de sincinesia & Ação M frontal & Sensibilidade \\
\hline Paralisis de Bell $(n=9)$ & HB I $(n=0)$ & Nenhum $(n=8)$ & grau 1 $(n=12)$ & Preservada \\
Neurinoma do acústico $(n=4)$ & HB II $(n=1)$ & Leve $(n=3)$ & grau 2 $(n=6)$ & $(n=20)$ \\
Sindrome de Ramsay Hunt & HB III $(n=2)$ & Moderado $(n=6)$ & grau 3 $(n=1)$ & \\
$(n=3)$ & HB IV $(n=11)$ & Severo $(n=3)$ & grau 4 $(n=1)$ & \\
FAF $(n=1)$ & HB V $(n=3)$ & & & \\
Paraganglioma $(n=1)$ & HB VI $(n=3)$ & & & \\
Colesteatoma $(n=1)$ & & & & \\
Iatrogenia $(n=1)$ & & & & \\
\hline
\end{tabular}

n=20 indivíduos. FAF: ferimento por arma de fogo, grau de PFP determinado pela escala de House e Brackmann (HB), grau de sincinesia determinado pela escala de Sunnybrook, ação do músculo frontal na hemiface paralisada graduado segundo escala de Sunnybrook. Sensibilidade testada pelo toque de algodão na pele da fronte, bilateral. 


\subsubsection{Documentação fotográfica}

A documentação fotográfica foi realizada em uma mesma sala com iluminação indireta, com o paciente sentado diante de painel de coloração preta. A máquina fotográfica foi posicionada a 1 metro de distância e na altura da face do paciente em posição frontal e repouso da mímica. Para evitar distorções na posição da cabeça foram observados os seguinte parâmetros:

- Posição neutra da cabeça evitando flexão ou extensão. Para isso a referência utilizada foi um plano horizontal desde o ponto superior do trágus até a margem inferior do rebordo orbitário inferior (semelhante à linha de Frankfurt utilizada em estudos cefalométricos).

- O alinhamento frontal e vertical seguiram a visualização simétricas das orelhas na foto.

\subsubsection{Avaliação objetiva computadorizada}

As medidas da posição dos supercílios foram realizadas por um profissional de informática cegado em relação a data ou identificação das fotos. Aleatoriamente foram incluídas 2 fotos de um indivíduo não operado, em dois intervalos diferentes, para conferir a confiabilidade das medidas. Neste caso as medidas foram semelhantes nos diferentes intervalos, sugerindo confiabilidade do método.

Para realização das medidas nas fotos este profissional desenvolveu um software onde o usuário determina linhas medindo a distância entre os pontos desejados na imagem. A calibração da distância em cada foto entre o ponto central das pupilas (estipulado em $6 \mathrm{~mm}$ ), permite interpretar as distâncias (pixels) em milímetros - Figura 1. Este método foi baseado em estudo prévio para mesma finalidade (da Cruz e Cruz, 2004).

Os pontos estipulados neste estudo, para padronização das medidas da posição dos supercílios, foram nos cantos palpebrais laterais e mediais e no centro das pupilas de ambos os olhos. A partir destes 6 pontos de referência foram traçadas linhas verticais de cada ponto até o limite superior do supercílio, estabelecendo uma reta. As retas foram denominadas conforme a figura 2. As medidas dos pacientes no início do estudo encontram-se na tabela 2. 
Figura 1 - Software desenvolvido para medir linhas determinadas pelo usuário, em vermelho. Linha interpupilar, em amarelo, utilizada para calibrar as medidas em cada imagem.

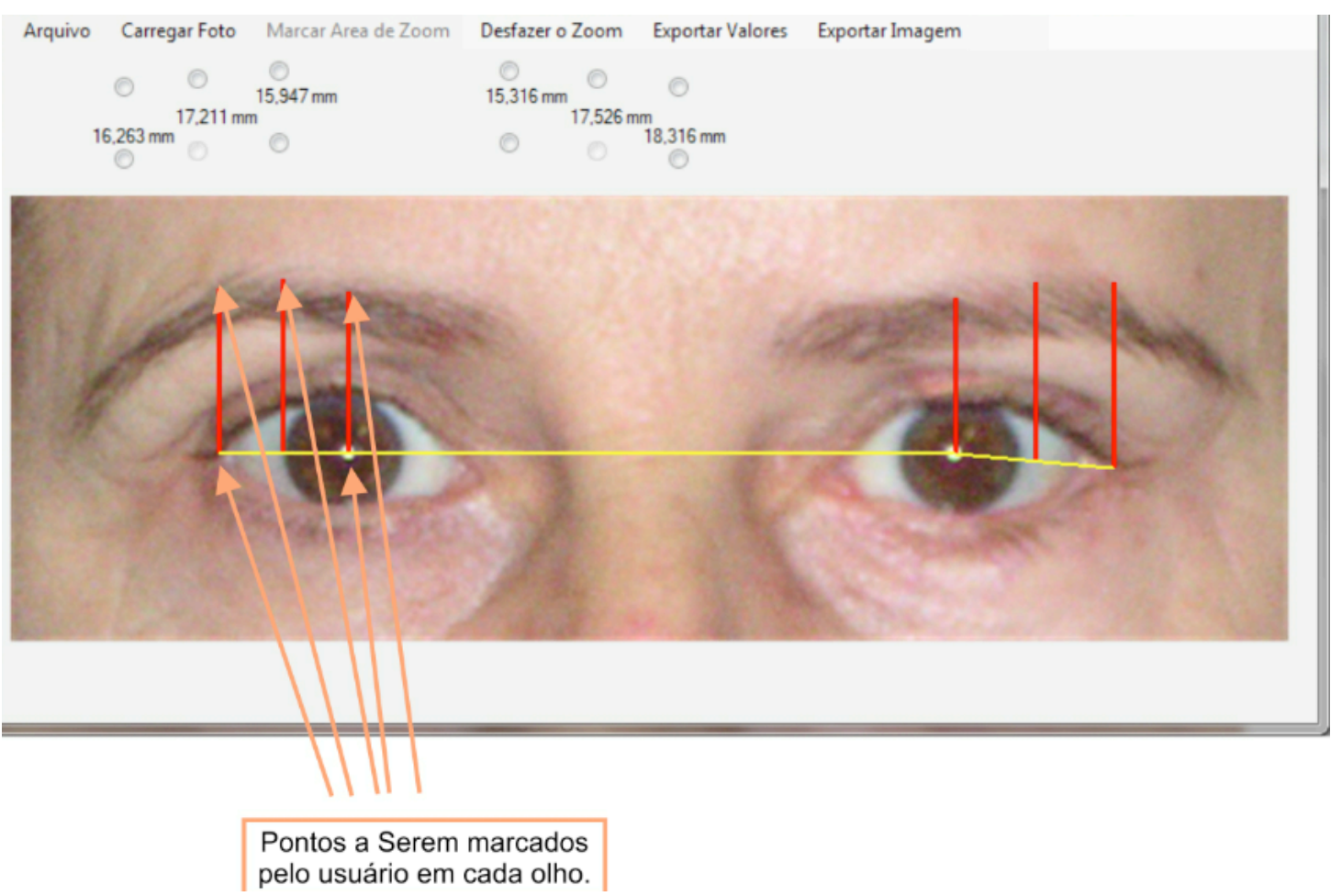

Figura 2 - Linhas verticais determinadas a partir dos pontos de referência até o limite superior dos supercílios.

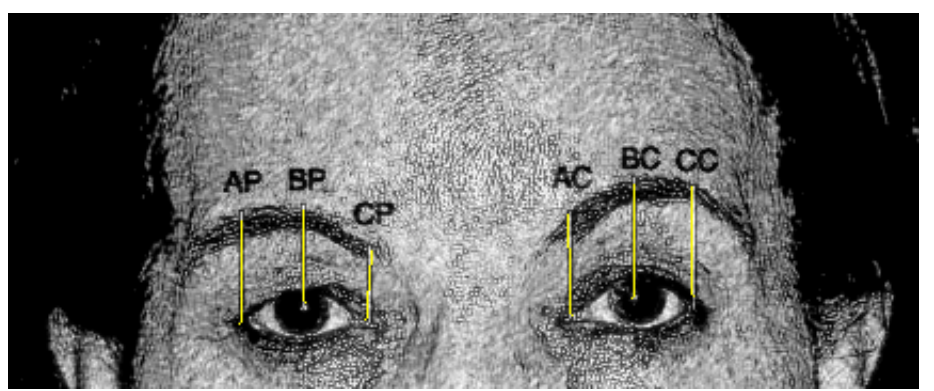

$\mathrm{AP}=$ canto lateral na hemiface paralisada, $\mathrm{BP}=$ centro da pupila na hemiface paralisada, $\mathrm{CP}=$ canto medial na hemiface paralisada, $\mathrm{AC}=$ canto lateral na hemiface contralateral, $\mathrm{BC}=$ centro da pupila na hemiface contralateral, $\mathrm{CC}=$ canto medial na hemiface contralateral 
Tabela 2 - Medidas verticais dos pontos de referência ao limite superior dos supercílios no início do estudo (T0), em milímetros

\begin{tabular}{lllllll}
\hline & $\mathrm{AP}$ & $\mathrm{BP}$ & $\mathrm{BC}$ & $\mathrm{AC}$ & $\mathrm{BC}$ & $\mathrm{CC}$ \\
\hline média & 19,80 & 19,51 & 18,97 & 19,92 & 18,97 & 18,82 \\
dp & $\pm 3,51$ & $\pm 3,36$ & $\pm 3,19$ & $\pm 3,84$ & $\pm 3,19$ & $\pm 3,16$ \\
mínima & 14,43 & 13,53 & 13,28 & 14,21 & 13,28 & 13,60 \\
máxima & 25,05 & 23,66 & 25,37 & 25,77 & 25,37 & 23,14 \\
\hline
\end{tabular}
$\mathrm{n}=20$ indivíduos
AP - Canto lateral da hemiface paralisada
BP - Centro da pupila da hemiface paralisada
$\mathrm{CP}$ - Canto medial da hemiface paralisada
$A C$ - Canto lateral da hemiface contralateral
$B C$ - Centro da pupila da hemiface contralateral
$\mathrm{CC}$ - Canto medial da hemiface contralateral

\subsection{Tratamento cirúrgico}

Os pacientes foram submetidos a frontoplastia bilateral sob sedação endovenosa (Midazolan 5mg) e anestesia loco-regional com cloridrato de lidocaína à $2 \%$ sem vasoconstritor $(\text { Xylestesin } ®)^{2}$ acrescida de adrenalina na proporção de 1:80.000 (Drenalin $\circledast)^{3}$. O preparo inicial na sala de cirurgia incluiu a lavagem dos cabelos e da face com solução degermante de clorexedina, seguido pelo enxágüe com água destilada esterilizada e colocação de campos cirúrgicos esterilizados.

Foram realizadas duas incisões temporais (uma em cada lado) com bisturi de lâmina fria no couro cabeludo, na região da linha temporalis. Cada incisão mediu aproximadamente $2,5 \mathrm{~cm}$ e foi localizada $1,5 \mathrm{~cm}$ acima da linha triquial. A seguir foi realizada dissecação do retalho temporal, seguindo plano subgaleal em direção ao rebordo orbitário lateral, evitando danos a vasos e nervos sobrejacentes. O descolamento frontal (figura 3 ) e posterior secção da linha temporalis (figura 4) também foi realizado pelo plano sub-galeal, pela mesma incisão, com tesoura curva de ponta romba. O descolamento estendeu-se em toda região frontal, da incisão até o rebordo orbitário superior e lateral. Foi realizado o descolamento do arcus marginalis evitando os nervos supra troclear e supra orbital, através de palpação e delimitação anatômica, marcada na pele

\footnotetext{
${ }^{2}$ Cristália- Produtos Químicos Farmacêuticos Ltda., Itapira-SP-Brasil

${ }^{3}$ Ariston - Produtos Químicos Farmacêuticos Ltda., São Paulo-SP-Brasil
} 
(figura 5). O ramo temporal do nervo facial foi protegido de lesões, mantendo a dissecção no plano entre as fáscias temporais e respeitando o limite de $2 \mathrm{~cm}$ lateralmente à parte lateral do rebordo orbitário.

Foram realizados pontos de ancoragem com fio de Mononylon 2.0 $\left(\text { Ethilon }{ }^{8}\right)^{4}$, e fixação do retalho ao músculo temporal obtendo a desejada elevação do supercílio. Em alguns indivíduos foi necessário fixar a cabeça do supercílio pois encontrava-se abaixo do rebordo orbitário superior. Nestes, foi feita uma incisão extra no couro cabeludo, de $1 \mathrm{~cm}$ na direção da cabeça do supercílio, inserida agulha de Reverdin (figura 6), levando o fio à cabeça do supercílio. A agulha perfurou a pele na região com pelos e o fio foi exteriorizado na cabeça do supercílio. Externamente, o fio foi re-inserido na agulha fazendo ancoragem no tecido subcutâneo e direcionado pelo plano dissecado até a incisão extra para fixação, junto a gálea aponeurórica e periósteo.

As incisões foram suturadas com Mononylon 4.0 (Ethilon $\circledast)^{4}$ após a ressecção dos excessos de retalho, quando necessário. Foi realizada imobilização com Micropore $\AA^{5}$ em toda pele dissecada e curativo compressivo com atadura sobre a fronte. A atadura foi retirada após $48 \mathrm{~h}$ em domicílio. No $14^{\circ}$ dia foi realizada a retirada sutura externa do couro cabeludo e Micropore $\AA^{5}$ em ambulatório.

\footnotetext{
${ }^{4}$ Johnson \& Johnson Produtos Profissionais Ltda., São José dos Campos-SP-Brasil

${ }^{5} 3 \mathrm{M}$ do Brasil, Sumaré-SP-Brasil
} 
Figura 3

Figura 4

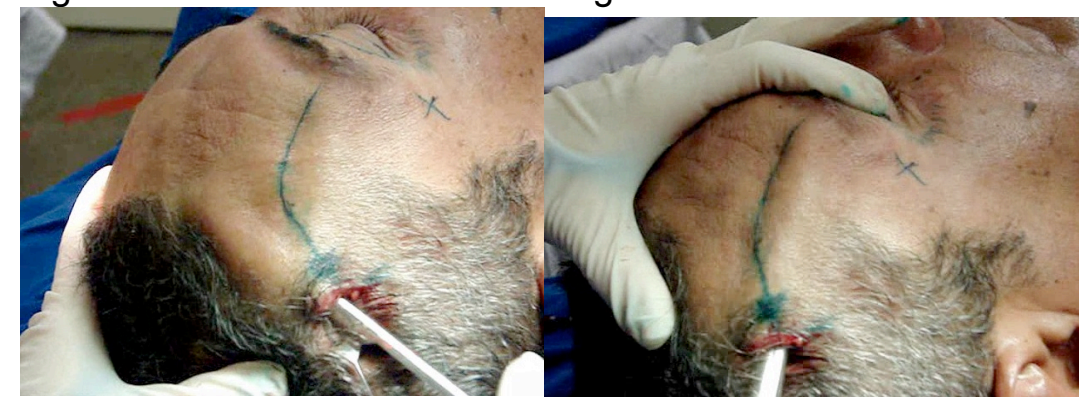

Figura 5

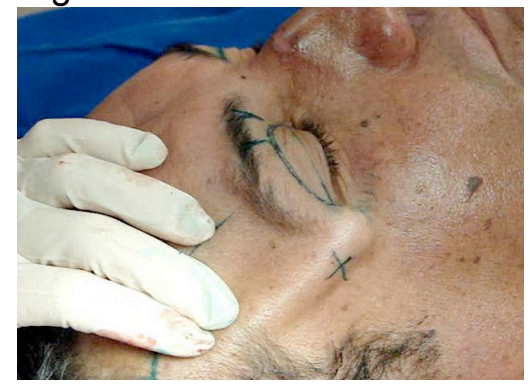

Figura 3 - Dissecção do retalho na porção frontal, através da incisão temporal.

Figura 4 - Identificação da Linha Temporal após a dissecção das porções temporal e frontal do retalho. A secção da linha temporal vai unir as duas porções criando um retalho único.

Figura 5 - Dissecção do retalho na região do Arcus marginalis, e liberação do mesmo raspando o periósteo do rebordo orbitário superior e lateral.

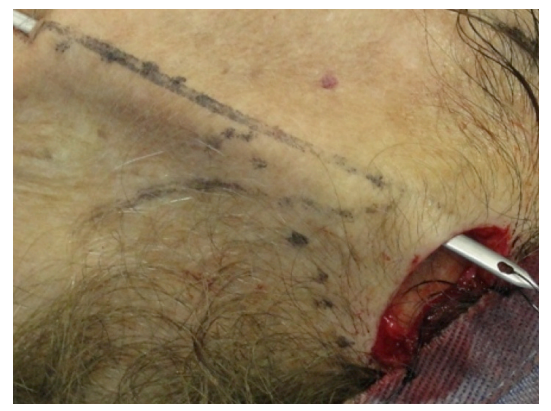

Figura 6 - Agulha de Reverdin utilizada para passagem do fio sob o retalho, fazendo ancoragem no tecido subcutâneo na altura da cabeça do supercílio, com posterior fixação na altura da incisão no couro cabeludo. 


\subsection{Tratamento clínico}

Os indivíduos que apresentavam sincinesia receberam aplicação intramuscular de toxina botulínica (Dysport $\circledast)^{6}$. As aplicações foram realizadas após a documentação fotográfica.

\subsection{Avaliação objetiva pós-operatória}

O mesmo padrão de documentação fotográfica foi realizado 12 e 24 meses após a cirurgia. Para os indivíduos que mantiveram o seguimento a documentação também prosseguiu anualmente, até 78 meses quando finalizou o estudo. Tabela 3

Tabela 3 - Intervalos de avaliação, em meses

\begin{tabular}{|l|l|}
\hline Intervalo & tempo após o início do estudo \\
\hline T0 & 0 meses - início do estudo \\
\hline T1 & 12 meses \\
\hline T2 & 24 meses \\
\hline T3 & 36 a 78 meses \\
\hline
\end{tabular}

\subsection{Avaliação subjetiva pós-operatória}

O grau de satisfação estética do paciente foi avaliado por questionário aplicado verbalmente 24 meses após a cirurgia, baseado em estudo prévio com seqüelas de PFP (Domingos, 2006). Primeira questão: "está satisfeito com o resultado?"; segunda questão: "como qualifica sua aparência após a cirurgia de 0 a 3 , sendo zero equivalente a pior, 1 indiferente, 2 melhor e 3 muito melhor".

\footnotetext{
${ }^{6}$ Ipsen Biopharm Ltd. Reino Unido, importado por Beaufour Ipsen farmacêutica Ltda. São Paulo
} 


\subsection{Avaliação clínica pós-operatória}

Os indivíduos operados foram avaliados 14 dias após a cirurgia, quando foi removida a sutura e curativos. Após 30 dias de cirurgia foi realizada nova avaliação, ocasião na qual foi verificada clinicamente a posição dos supercílios e testada novamente a função do músculo frontal, segundo escala de Sunnybrook (anexo C) e sensibilidade cutânea pelo toque com algodão. As queixas e complicações decorrentes da cirurgia foram observadas nestas e demais visitas agendadas aos 3 e 6 meses pós-operatório, bem como nos demais intervalos estipulados para documentação fotográfica.

\subsection{Análise dos resultados e estatística}

Para análise estatística comparativa foram variáveis de estudo: medidas da posição dos supercílios na linha AP das fotos dos mesmos indivíduos, em 2 momentos:

- Pré-operatório (T0)

- Pós 24 meses de cirurgia (T2)

Exploratoriamente foram comparadas as diferenças pré e pós-operatórias:

- Pós 12 meses de cirurgia (T1)

- Pós 36 até 78 meses de cirurgia (T3)

Consideramos normal a distribuição das variáveis após realização do teste de Kolmogorov-Smirnov. A comparação entre os diferentes períodos de avaliação foi feito pelo teste T pareado, em testes bicaudais com intervalo de confiança de $95 \%$. Foi considerado diferença com significância estatística para valores de $p$ menores que $5 \%$ (software SPSS Statistics versão 17.0).

Para os dados descritivos com distribuição normal foi calculada média e desvio padrão, para não normal mediana e intervalo interquartil.

Os resultados dos questionários foram avaliados qualitativamente.

\subsubsection{Cálculo da amostra}

O cálculo da amostra foi efetuado a partir dos resultados obtidos em projeto-piloto, estimado em 5 pacientes (software STATA versão 10.0. 
5. RESULTADOS 


\section{Resultados}

\subsection{População estudada}

As 20 cirurgias foram realizadas de janeiro de 2006 a outubro de 2009, no HC da FMUSP, SP, e 1 indivíduo foi excluído pós interrupção do ato cirúrgico, devido a arritmia cardíaca. Os pacientes foram acompanhados de janeiro de 2006 a outubro de 2013. Dos 19 indivíduos operados, 8 compareceram para a avaliação em T2 , 24 meses após a cirurgia. Quatro não compareceram as visitas de seguimento do estudo e foram considerados como perdas na casuística (gráfico 1). As características destes indivíduos encontram-se na tabela 4 e a média das medidas realizadas nas 3 linhas verticais, dos 2 supercílios no pré-operatório encontram-se no gráfico 2. Foram realizadas cirurgias concomitantes em 6 dos indivíduos, sendo 2 submetidos a implante palpebral de peso de ouro, 4 submetidos a blefaroplastia superior e 1 destes com blefaroplastia inferior.

Gráfico 1 - Fluxograma do número de indivíduos incluídos na casuística e quantos compareceram em cada intervalo de avaliação pós-operatória.

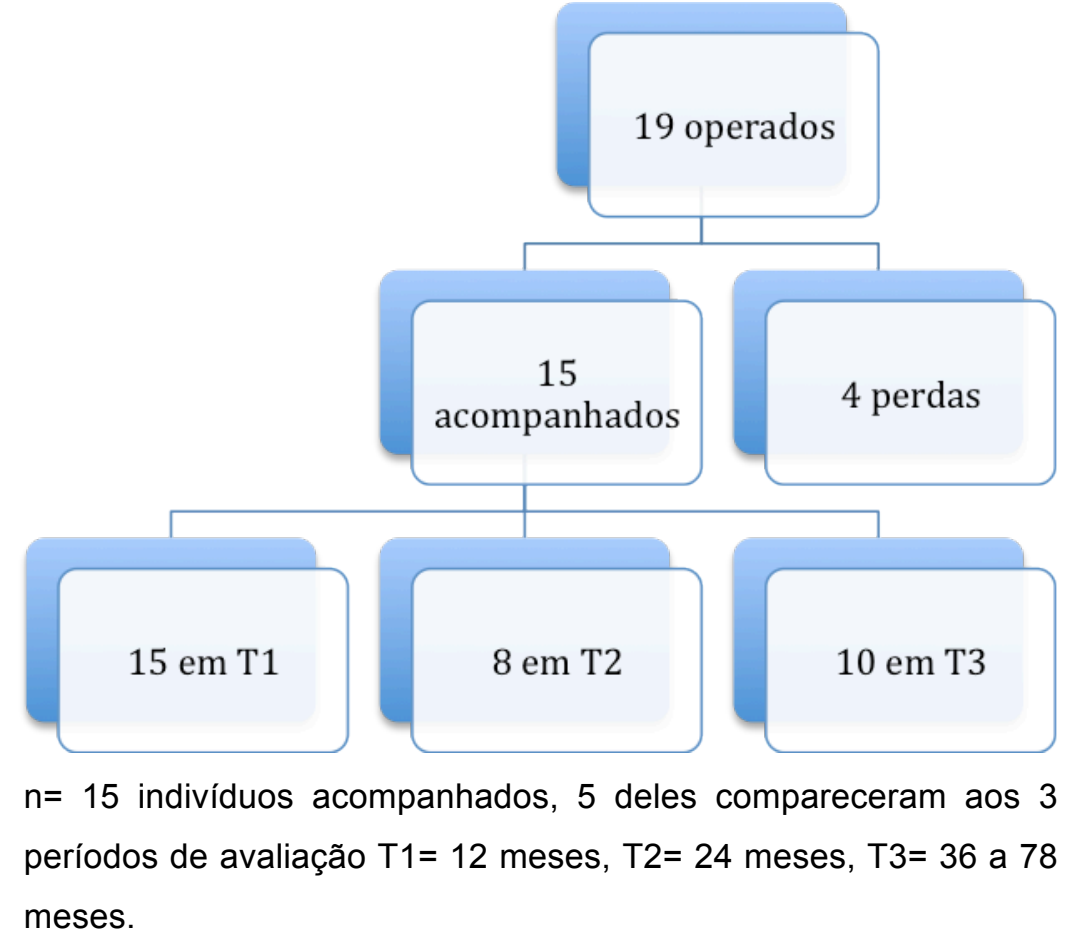


Tabela 4 - Características da população acompanhada aos 24 meses após a cirurgia.

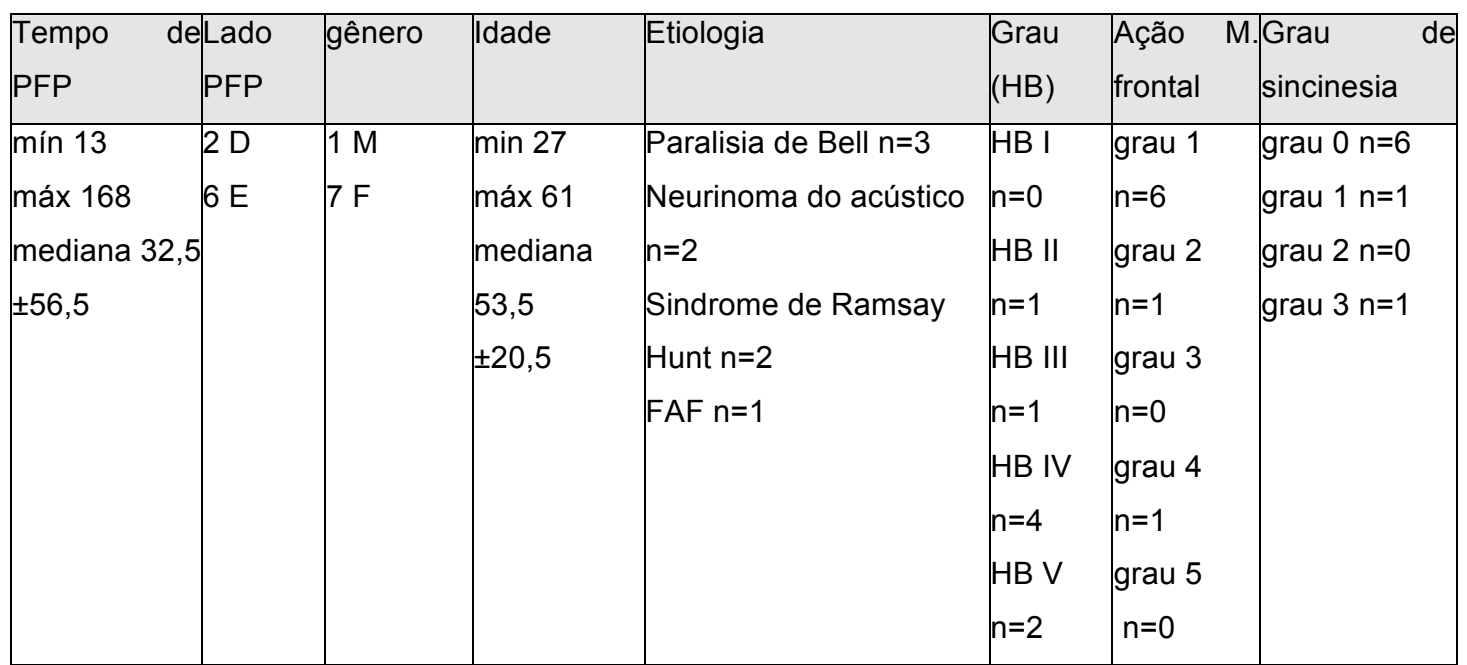

n=8 indivíduos, Tempo de PFP em meses, D: lado direito, E: lado esquerdo, M: masculino, $\mathrm{F}$ feminino, FAF:Ferimento por arma de fogo, Grau HB: grau de paralisia facial segundo escala de House e Brackmann (anexo B), graus de ação do músculo frontal e sincinesia: segundo escala de Sunnybrook (anexo C).

Gráfico 2 - Médias da posição dos 2 supercílios no pré-operatório, em todas as linhas, em milímetros, $n=15$

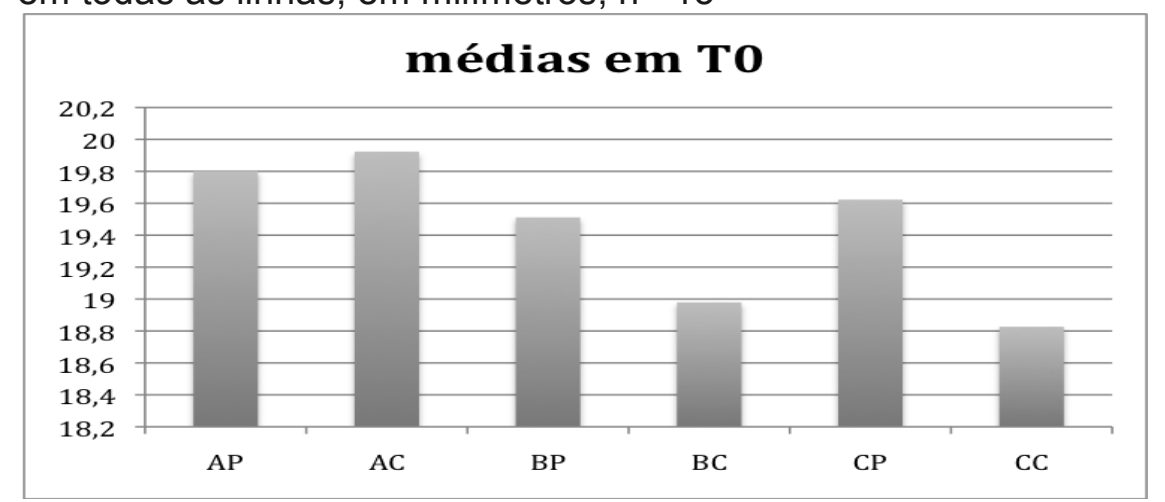

AP - Canto lateral da hemiface paralisada; média 19,8 dp 3,51

BP - Centro da pupila da hemiface paralisada; média 19,5 dp 3,36

CP - Canto medial da hemiface paralisada; média 19,8 dp 2,86

AC - Canto lateral da hemiface contralateral; média 19,92 dp 3,84

BC - Centro da pupila da hemiface contralateral; média 18,9 dp 3,19

CC - Canto medial da hemiface contralateral; média 18,8 dp 3,16 


\subsection{Avaliação objetiva}

Foi realizada comparação das medidas obtidas nas fotos destes indivíduos antes da cirurgia (T0) e 24 meses após (T2) na linha AP estabelecida verticalmente do canto palpebral lateral na hemiface paralisada, ao ponto mais alto do supercílio deste mesmo lado. Houve diferença estatisticamente significativa através do teste T pareado entre o pré e pósoperatório, em testes bicaudais com intervalo de confiança de 95\% - cujos resultados encontram-se na tabela 5 .

Tabela 5 - Comparação das medidas, em milímetros, obtidas na linha AP entre T0 e T2.

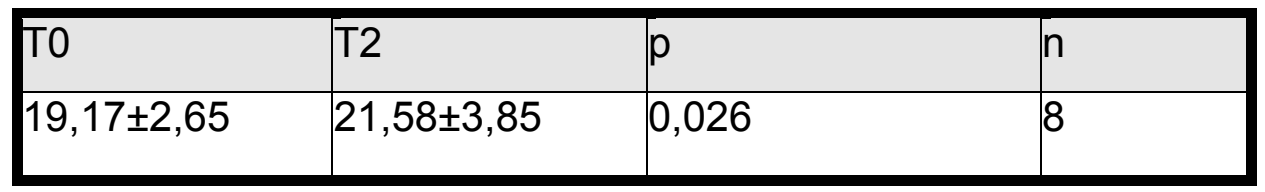

Linha $\mathrm{AP}=$ canto lateral da hemiface paralisada ao limite superior do supercílio $\mathrm{T} 0=$ pré-operatório, $\mathrm{T} 2=$ pós 24 meses de cirurgia, $\mathrm{p}=$ valor de p.

Os dados foram estatisticamente manipulados segundo "intenção de tratar", completando as variáveis dos pacientes que faltaram às visitas de 24 meses totalizando 15 indivíduos. Para esta manipulação estatística foi utilizado o critério de "pior cenário" (ou seja, T2 = T0). A diferença entre T0 e T2 manteve-se estatisticamente significativa, conforme a tabela 6.

Tabela 6 - Comparação das medidas obtidas na linha AP em 15 indivíduos entre pré e 24 meses pós-operatório, segundo a intenção de tratar, pelo "pior cenário" (T2 = T0).

\begin{tabular}{|l|l|l|l|}
\hline T0 & T2 & $\mathrm{p}$ & $\mathrm{n}$ \\
\hline $19,8 \pm 3,5$ & $21 \pm 4$ & 0,034 & 15 \\
\hline
\end{tabular}

T0 = pré-operatório, $\mathrm{T} 2$ = pós 24 meses de cirurgia, $p=$ valor de $p$ 
Segundo a intenção de tratar os dados dos faltantes em T2 foram considerados os valores médios obtidos entre T1 e T3 destes mesmos indivíduos; para os faltantes em T3 foram repetidos os valores de T0. A diferença manteve-se estatisticamente significativa para 15 indivíduos conforme a tabela 7.

Tabela 7 - Comparação das medidas obtidas na linha AP entre pré e 24 meses pós-operatório, completando os faltantes com as médias obtidas entre T1 e T3, segundo a intenção de tratar.

\begin{tabular}{|l|l|l|l|}
\hline T0 & T2 & p & n \\
\hline $19,8 \pm 4,1$ & $21,4 \pm 3,5$ & 0,017 & 15 \\
\hline
\end{tabular}

$\mathrm{T} 0=$ pré-operatório, $\mathrm{T} 2$ = pós 24 meses de cirurgia, $\mathrm{p}=$ valor de $\mathrm{p}$

Exploratoriamente foi mensurada a linha AP, em milímetros, nos 10 indivíduos que compareceram para avaliação em T1 e T3, conforme Tabela 8.

Tabela 8 - Média das medidas da linha AP em T1 e T3, em milímetros.

\begin{tabular}{|l|c|l|l|}
\hline T0 & T1 & T3 & $n$ \\
\hline $20 \pm 3,7$ & $21,9 \pm 3,6$ & $22,4 \pm 3,8$ & 10 \\
\hline
\end{tabular}

$\mathrm{T} 0=$ pré-operatório, $\mathrm{T} 1=12$ meses pós-cirurgia, $\mathrm{T} 3=36$ a 78 meses pós-cirurgia. 
O gráfico 3 ilustra a comparação da medida de todas as linhas utilizadas para aferir a posição dos 2 supercílios, nos diferente intervalos de avaliação.

Gráfico 3 - Comparação das medidas dos supercílios em todas as linhas, em todos os intervalos, em milímetros.

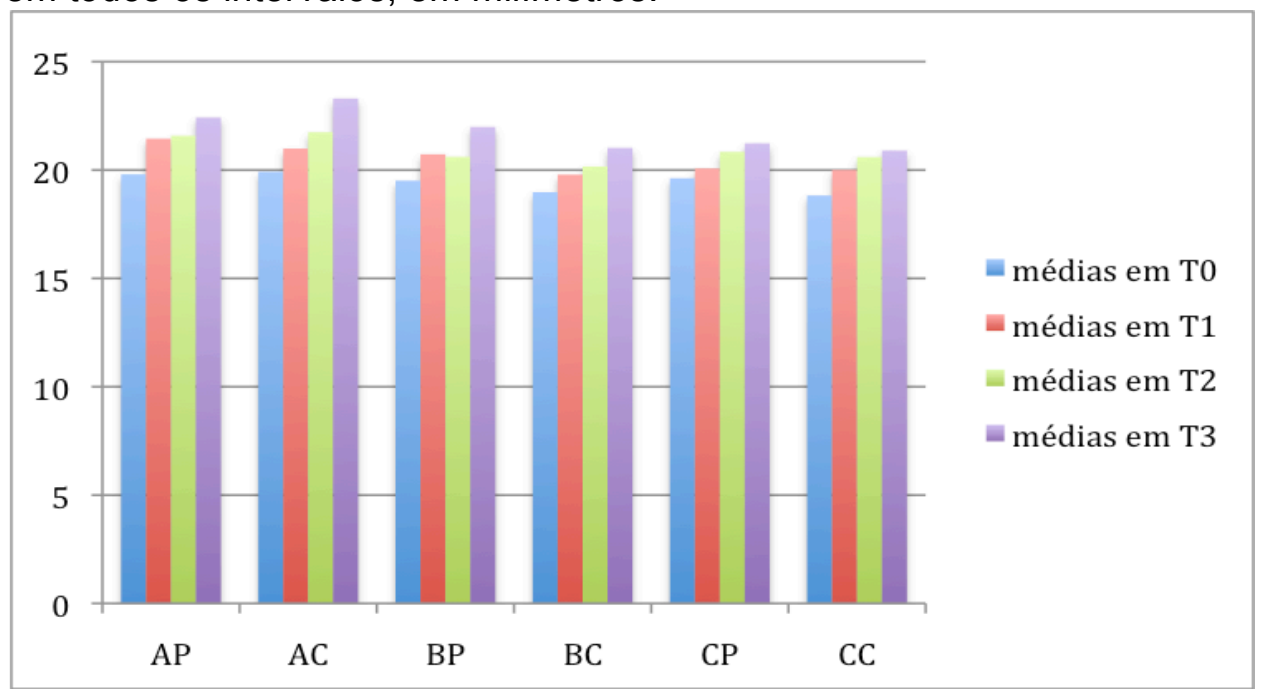

$\mathrm{AP}=$ canto lateral na hemiface paralisada, $\mathrm{BP}=$ centro da pupila na hemiface paralisada, $\mathrm{CP}=$ canto medial na hemiface paralisada, $\mathrm{AC}=$ canto lateral na hemiface contralateral, $\mathrm{BC}=$ centro da pupila na hemiface contralateral, $\mathrm{CC}=$ canto medial na hemiface contralateral; $\mathrm{T} 0=$ préoperatório, $n=15$; T1=pós-operatório12 meses, $n=15$; T2=pós-operatório 24 meses, $n=8$; T3=pós-operatório de 36 a 78 meses, $n=10$.

\subsection{Avaliação subjetiva:}

O resultado do questionário de satisfação mostrou que os 8 indivíduos encontravam-se satisfeitos com o resultado da cirurgia, após 24 meses. Nenhum declarou estar insatisfeito. O gráfico 4 ilustra o número de indivíduos que responderam entre os diferentes graus de satisfação.

Gráfico 4 - Grau de satisfação dos indivíduos com a cirurgia. n=8 indivíduos, questionados 24 meses após a cirurgia. grau 0: pior, grau 1: igual, grau 2: melhor, grau 3: muito melhor.

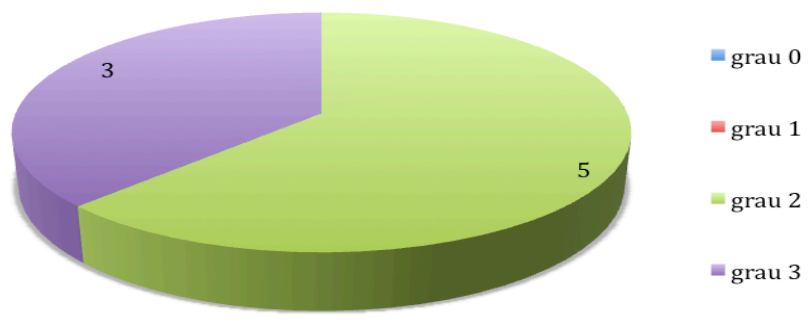




\subsection{Avaliação clínica pós-operatória}

Nesta amostra não foram observadas perdas da função neural sensitiva ou motora em decorrência da cirurgia. A sensibilidade e ação do músculo frontal foram testadas 1 mês após a realização da cirurgia.

\subsubsection{Complicações das cirurgias}

Houve 1 caso de rompimento precoce da sutura de fixação interna, diagnosticado pela observação de ptose do supercílio na avaliação clínica realizada 14 dias pós-operatório. Foi novamente operado para nova fixação utilizando a mesma via de acesso no couro cabeludo para fixação do retalho, que foi bem sucedida. Dois pacientes apresentaram reação ao fio de sutura no período de 6 a 12 meses pós operatório. Estes casos foram resolvidos com a remoção ambulatorial do nó da sutura, que estava se exteriorizando no couro cabeludo, sem prejuízo ao resultado. Um indivíduo relatou que sentiu sensação de formigamento na região frontal por 3 meses, após a cirurgia, e melhorou espontaneamente. 
6. DISCUSSÃO 


\section{Discussão}

\subsection{Metodologia e limitações da pesquisa}

Esta amostra foi composta por 20 pacientes adultos que sofreram paralisia facial periférica e permaneceram com sequela frontal por mais de 12 meses e ptose sintomática do supercílio. A indicação de uma cirurgia pode ter finalidade estética para recuperar a simetria da face em repouso e/ou funcional para eliminar o tecido palpebral superior redundante sobre o campo visual. Outras publicações com PFP avaliaram de 3 até 51 casos (Ueda et al., 1994; Yamamoto et al., 2001; Constantino et al., 2003; Ducic e Adelson 2005), porém foram retrospectivos e não estabeleceram critérios de inclusão. O estudos de Takushima et al. (2003) e Rautio e Pignatti (2001) foram prospectivos mas nenhum deles especificou critérios de inclusão como idade ou tempo de paralisia, portanto incluíram crianças e talvez paralisia aguda.

Apesar de modesta, esta foi uma amostra de conveniência de um ambulatório especializado em PFP no HC da FMUSP - um hospital de referência no Brasil. O ideal seria um estudo multicêntrico randomizado controlado porém, diante da escassez de pesquisas de qualidade sobre o tema, esta é uma contribuição significativa para o desenvolvimento da ciência nesta área. Com maior amostragem, outra possibilidade seria a da formação de grupos de pacientes com graus semelhantes de sequela frontal para comparação. Neste estudo, optamos por avaliar os casos de ptose de supercílio leve ou moderada por questões éticas, devido a maior probabilidade de resultados eficazes, em se tratando de estudo pioneiro em pacientes com estas características.

O resultado obtido com a realização da frontoplastia é estético, portanto a busca da avaliação com critérios mais objetivos é um desafio ao pesquisador. Em outras publicações avaliando frontoplastia pós PFP (Ueda et al., 1994; Rautio e Pignatti, 2001; Yamamoto et al., 2001; Constantino et al., 2003, Ducic e Adelson, 2005) as avaliações foram subjetivas ou por medidas manuais realizadas pelo próprio cirurgião e sua equipe, o que aumenta a possibilidade de vieses. Outros descreveram técnicas e plano de tratamento, sem casuística. (Meltzer e Byrne, 2008). Graham et al. (2011) após revisão sistemática da 
literatura, observaram que faltam estudos consistentes com padronização de medidas na evolução pós-operatória.

Takushima et al. (2003) utilizaram as medidas computadorizadas nas fotos, porém realizadas pelos próprios pesquisadores. O presente estudo utilizou medidas computadorizadas, cuidando para que fossem realizadas por alguém alheio ao estudo, reduzindo vieses. Além disso foi realizada a calibração pela distância inter pupilar em cada foto que foi aferida. Este procedimento evita que as diferenças entre as fotos interfiram no resultado, permitindo comparação entre fotos feitas em diferentes períodos.

O canto lateral palpebral foi selecionado como referência para avaliação da suspensão do supercílio pelo fato de ser fixo e estar verticalmente próximo ao ponto mais alto do supercílio. Segundo estudo antropométrico (Whitaker et al., 1986), o ponto mais alto do supercílio fica na transição do seu terço médio para o lateral, denominado supraciliare. Esta supra elevação está associada com o embelezamento. Durante a cirurgia procura-se criar ou restaurar este detalhe, razão pela qual na presente técnica corresponde verticalmente à região do retalho escolhida para fixação.

Optou-se por estabelecer o período de avaliação pós-operatória em 24 meses, considerando que em até 12 meses pode ocorrer queda do supercílio, conforme observaram Ueda et al., (1994) avaliando 40 indivíduos pós-correção de ptose de supercílio por PFP. Para que a cirurgia seja eficiente é importante que o resultado seja durável. Nenhum estudo prospectivo com PFP realizou acompanhamento sistemático dos pacientes além de 12 meses (Rautio e Pignatti 2001; Takushima et al., 2003), já neste estudo foi realizada a avaliação após 24 meses e exploratoriamente após 36 e até 78 meses em 15 indivíduos, fornecendo também dados a longo prazo.

Todos os pacientes se declararam satisfeitos com o resultado após 24 meses e qualificaram seu estado como "melhor" ou "muito melhor". Este resultado está coerente com o resultado objetivo, mas existem influências psicológicas do indivíduo por ter sido operado, além do receio por parte do mesmo em ferir o examinador ao declarar alguma insatisfação sobre o procedimento. Ainda assim, a satisfação do paciente é essencial e, nesse sentido, foi mantida a avaliação subjetiva como objetivo secundário nesta pesquisa. Em relação ao instrumento de avaliação, em estudo piloto, foi 
utilizada a escala de visualização analógica e apesar da simplicidade muitos não conseguiram responder. Por esta razão, optou-se por questões baseadas no estudo feito com portadores de PFP na mesma instituição, na tese de doutorado de Domingos, em 2002.

As complicações das cirurgias foram leves e reversíveis quando comparadas a casuísticas publicadas utilizando técnicas semelhantes, como queimadura por eletro coagulação, queda do supercílio e alopecia (Rautio e Pignatti, 2001). No presente estudo não houve recidiva da ptose, mas 1 caso de ruptura da fixação no pós operatório imediato, que foi corrigido com recuperação completa da elevação do supercílio. Dois casos apresentaram reação tardia ao fio utilizado para fixação do supercílio necessitando remoção, este procedimento não provocou recidiva da ptose nestes indivíduos.

\subsection{Técnica cirúrgica:}

A frontoplastia direta com ressecção cutânea sobre o limite superior do supercílio é a técnica favorita para tratamento da ptose por PFP (Ueda et al., 1994; May, 2000; Meltzer e Byrne, 2008). Entre as vantagens é considerada tecnicamente mais fácil, rápida e os resultados mais previsíveis a curto e longo prazo. Consideramos esta técnica muito útil para casos de ptose acentuada e pacientes de maior risco anestésico. Em idosos a cicatriz pode se tornar inconspícua, nos mais jovens não, por isso, neste grupo outras técnicas estão sendo preferidas. Entre elas a frontoplastia endoscópica, descrita por Vasconez et al. em 1992 (appud Ramirez, 1994) para rejuvenescimento facial, com menores incisões e menos complicações comparando à frontoplastia coronal.

Rautio e Pignatti (2001); Takushima et al. (2003) e Ducic e Adelson (2005), utilizaram a frontoplastia endoscópica para correção de supercílios pósparalisia facial com resultados satisfatórios. A utilização do endoscópio é vantajosa pois, a visualização das estruturas torna o procedimento mais seguro e possibilita a combinação de miotomias sem necessidade de incisões adicionais. Entretanto, a frontoplastia não endoscópica também tem se mostrado eficaz e segura e ainda apresenta vantagens como menor custo e maior rapidez do procedimento, com o que concordam Tabatai e Spinelli (2007). 
Alguns autores (Kikkawa et al., 2000; Marten, 2008) também consideraram desnecessário o uso do endoscópio para realização da cirurgia por pequenas incisões, tornando o procedimento mais rápido, sem necessidade de equipamento e treinamento especializados, com resultados eficazes em PFP (Constantino et al., 2003; Meltzer e Byrne, 2008), porém, estas publicações foram baseadas em opiniões pessoais ou avaliação retrospectivas sem seguimento a longo prazo, desta forma o presente estudo fornece dados que contribuem com o conhecimento da técnica não endoscópica em indivíduos com PFP.

Yamamoto et al. (2001), descreveram uma frontoplastia com mínimas incisões com descolamento do retalho realizado sem endoscópio, seguido da visualização endoscópica dos feixes vásculonervosos. A possibilidade de associar as duas técnicas pode auxiliar no aperfeiçoamento do procedimento e aumentar a segurança durante a liberação dos ligamentos do arcus marginalis. Entretanto estes autores relataram apenas 3 casos, necessitando mais estudos a este respeito.

A técnica não endoscópica com incisões limitadas foi descrita por Knize em 1996, para rejuvenescimento com base na dissecção de cadáveres. Neste estudo observou os reparos anatômicos para evitar danos a vasos e nervos da região, notadamente do ramo temporal do nervo facial. Este autor operou e acompanhou 140 pacientes, concluindo que com o domínio dos reparos anatômicos e manutenção do plano de dissecção, a cirurgia foi segura, eficiente e mais rápida que a endoscópica. Em 2007, Tabatai e Spinelli também obtiveram sucesso em 93 casos operados para rejuvenescimento, sem endoscópio. A frontoplastia não endoscópica é utilizada para rejuvenescimento frontal e após algumas modificações, foi utilizada neste estudo. Para o sucesso desta técnica a anatomia deve ser bem conhecida para possibilitar adequada dissecação e liberação dos ligamentos, sem visualização. Este ponto da cirurgia é essencial para elevação bem sucedida do retalho frontal, conforme o conceito "funcional" descrito na frontoplastia endoscópica (Isse, 1994).

A frontoplastia endoscópica foi descrita pelo plano subperiostal em parte pela facilidade de visualização com a óptica, devido ausência de vasos neste plano, aliada a maior rigidez do periósteo contribuindo com a firmeza do retalho (Ramirez 1994). Outros autores preferem a combinação do subperiostal na 
parte central da fronte ao plano subgaleal nas regiões laterais (Isse NG, 1994). Mas a cirurgia também pode ser realizada pelo plano subgaleal com resultados semelhantes, permitindo ainda elevação seletiva de partes do supercílio, devido a maior maleabilidade do retalho. Por esta razão, este plano foi selecionado para o presente estudo se obtendo eficiência, com poucos efeitos indesejados.

Nesta casuística, a fixação com sutura de Mononylon® 2.0 no músculo temporal e gálea aponeurótica, mostrou-se suficiente para o grau de suspensão e permanência almejados, além disso não houve queda no intervalo avaliado, lembrando que o grau de ptose nesta amostra foi moderado. Não existe consenso entre os autores quanto a técnicas e materiais utilizados para fixação do retalho (Isse, 1994; Ramirez, 1994; Kenedy e Pogue, 1999). Outros autores que utilizaram a frontoplastia endoscópica, ou não, com mínimas incisões, em indivíduos com PFP realizaram fixações mais rígidas como sutura ao pericrânio (Constantino et al., 2003) e parafusos permanentes (Kikawa et al., 2000; Rautio e Pignatti, 2001; Takushima et al., 2003). Kenedy e Pogue (1999) aconselharam o uso de materiais mais rígidos para elevações superiores a $0,5 \mathrm{~cm}$. Troillius (2004) avaliando retrospectivamente indivíduos operados para suspensão estética do supercílio, concluiu que para elevações de até $4 \mathrm{~mm}$ não há necessidade de fixação do retalho. Talvez exista uma correlação entre o tipo de fixação e magnitude de suspensão do supercílio, sendo assim a fixação com parafusos permanentes poderia favorecer indivíduos com ptose acentuada, ainda que o presente estudo não tenha poder para sustentar esta hipótese.

$\mathrm{Na}$ frontoplastia endoscópica a liberação dos ligamentos do arcus marginalis e ressecção parcial dos músculos depressores do supercílio favorecem a ação da musculatura frontal, responsável pela elevação do supercílio (Isse, 1994). O mesmo efeito pode ser esperado na frontoplastia por mínimas incisões. Por esta razão na paralisia residual do músculo occipitofrontal haveria suspeita de insucesso, mas os poucos trabalhos publicados até o momento mostram o contrário (Rautio e Pignatti, 2001; Constantino et al., 2003; Takushima et al., 2003; Ducic e Adelson 2005). Neste estudo também observou-se elevação adequada e manutenção do resultado após 24 meses, tanto na hemiface com função normal quanto com paralisia 
residual, mesmo sem a realização de miotomias nos músculos depressores do supercílio. Uma hipótese é a de que pela confecção e suspensão de retalho único, liberação dos ligamentos retentores, aliada a função muscular occipitofrontal contralateral, a elevação dos supercílios possa ter sido favorecida. Dos 20 indivíduos operados, 18 deles (90\%) apresentavam apenas discreta ação residual do músculo frontal, o que pode ser considerado paradoxal pelo conceito de cirurgia funcional, que depende da ação do músculo frontal. Não há até o momento explicação para este efeito. Em indivíduos com melhor ação do músculo frontal, ou sem paralisia, este mecanismo de elevação pós-cirurgia pode ser otimizado. Este seria um possível tema para futuros estudos, elucidando o mecanismo de elevação adicional do supercílio no período pós-operatório.

Por se tratar de uma cirurgia de suspensão estática, a paralisia residual do músculo frontal não é abordada. Para esta finalidade seria ideal uma cirurgia de reconstrução dinâmica como transferência neural (Burgess e Goode, 1994). Entretanto, existe um consenso entre os autores de que a suspensão estática é preferida na fronte, devido ao resultado insatisfatório das reconstruções dinâmicas nesta região (Sobol e May,1991; Stennert E, 1994; De Rossi et al., 2011). Por esta razão a frontoplastia foi selecionada para correção da ptose de supercílio em indivíduos com paralisia residual do músculo frontal.

A assimetria dinâmica do supercílio não foi abordada, sendo esta uma das limitações da frontoplastia, em geral. Uma possibilidade de minimizar esta deficiência foi idealizada por Rubin em 1991, através de um prolongamento do músculo frontal sadio para suspender dinamicamente o lado comprometido, porém faltam estudos demonstrando os resultados deste procedimento. Outra maneira de mascarar a assimetria dinâmica seria através da aplicação de Toxina Botulínica, paralisando quimicamente o músculo frontal sadio, favorecendo o resultado final. $O$ benefício deste procedimento associado a cirurgia é consenso entre os autores (Freeman, 1979; Gulane e Cheng, 1991; Parnes e Batniji, 2001; Clark e Shockley, 2002; Hadlock et al., 2006; De Rossi et al., 2011).

Outra possibilidade para se obter equilíbrio muscular frontal, seria a da realização de neurectomia seletiva do ramo temporal do nervo facial contralateral. Este procedimento foi descrito sob visualização endoscópica no 
mesmo ato operatório, provocando paralisia definitiva do músculo frontal contralateral e favorecendo a simetria (Moody et al., 2001). Esta manobra deve ser bem programada por se tratar de procedimento irreversível e também necessita de estudos para analisar o efeito resultante na fronte e supercílios.

A técnica de frontoplastia por mínimas incisões, sem o auxílio de endoscópio, não permite a visualização e ressecção dos músculos depressores do supercílio. O acesso a estes músculos pode ser feito pela incisão da blefaroplastia superior como descrito por Knize (1996), e Kikkawa et al. (2000). Em indivíduos com PFP as miotomias podem auxiliar no equilíbrio entre a musculatura das hemifaces; este efeito pode ser obtido por enfraquecimento do lado sadio ou do lado que tenha sequelas hipercinéticas pós PFP (sincinesia, espasmo ou contratura). Doze dos 20 indivíduos incluídos nesta amostra (60\%) apresentavam sincinesia e foram tratados com aplicações de Toxina Botulínica após a realização das fotos do estudo. Dos 8 pacientes que completaram a avaliação de 24 meses apenas 2 apresentavam sincinesia (25\%). Ainda que estas aplicações possam ter influenciado na posição do supercílio favorecendo sua elevação, não seria ético evitá-las. Para minimizar esta influência as aplicações foram feitas após as fotos, já que o efeito da medicação tem duração de 90 dias, tempo inferior ao período de avaliação do estudo.

A quantidade de suspensão dos supercílios obtida após a cirurgia, em milimetros pode ser considerada pequena, mas como em toda cirurgia estética dificilmente existe um padrão a ser obtido da posição ideal do supercílio - os critérios de ideal de beleza variam entre os autores (Freund e Nolan, 1996; Gunter e Antrobus, 1997). A quantidade de elevação do supercílio com a cirurgia pode variar de acordo com os conceitos de beleza. Neste estudo o supercílio foi reposicionado sobre o rebordo orbitário, com leve acentuação da transição entre o terço médio e lateral, conferindo naturalidade ao resultado. 0 valor médio da posição do supercílio paralisado na linha AP passou de 19,17 a $21,58 \mathrm{~mm}$, no intervalo pós-operatório de 24 meses, resultado adequado quando comparado ao estudo feito por Matros et al. (2009), que por método semelhante mediu o supercílio de indivíduos sem PFP. Os valores encontrados no canto lateral destes indivíduos sem PFP foram, em média de 21,3 mm no grupo de 20 a 30 anos e de 22,4 mm, no grupo de 50 a 60 anos. 


\subsection{Resultado cirúrgico}

A elevação do supercílio, usualmente, vai se opor ao fechamento ocular, entretanto, se a cirurgia for conservadora, associada com implante de peso de ouro, quando necessário, há menos risco. No presente estudo, dos 8 pacientes que foram avaliados em T2, 4 indivíduos (50\%) realizaram blefaroplastia superior e 2 (25\%) colocação de implante de peso de ouro na pálpebra superior no mesmo ato cirúrgico. Não ocorreu dificuldade de fechamento palpebral em nenhum paciente após a cirurgia.

A cirurgia palpebral também pode, potencialmente, se contrapor à suspensão, devido a tração inferior do supercílio ocasionada pela retirada de pele e posterior retração cicatricial das pálpebras. Isso pode ocorrer nas ressecções excessivas de pele, mas no presente estudo a blefaroplastia foi conservadora, minimizando este efeito. Troillius (2004), comparou grupos de pacientes que realizaram, ou não, blefaroplastia concomitante a frontoplastia e concluiu que não houve diferença no resultado de elevação do supercílio entre os grupos.

Nesta casuística a frontoplastia não endoscópica, por mínimas incisões, mostrou-se eficaz para elevação do supercílio pós PFP. A diferença pré e pósoperatória foi estatisticamente significativa para os 8 indivíduos que compareceram para avaliação 24 meses após a cirurgia e também para os 15 que completaram 36 meses ou mais, seguindo a correção estatística, ainda que pelo "pior cenário". Clinicamente os resultados também foram satisfatórios e não houve necessidade de nova cirurgia para correção até o término da pesquisa.

Observou-se exploratoriamente que, tardiamente, a linha AP na hemiface paralisada passou em média de 21,9 aos 12 meses a 22,4 mm após 36 a 78 meses. Da mesma forma, no gráfico com as médias de elevação obtidas em todos os pontos, nos diferentes intervalos deste estudo, verificou-se aparente elevação na posição dos dois supercílios com o passar do tempo. Em uma série de pacientes submetidos a frontoplastia coronal por finalidade estética, a medida no canto lateral do supercílio também aumentou em média 2,5 mm, no período de 1 a 5 anos, após a cirurgia (Troilius, 2004). Este achado pode ser paradoxal uma vez que devido a ação gravitacional, ação dos 
músculos depressores e perda da sustentação do retalho, se espera queda do supercílio com o passar do tempo (Whitaker et al., 1986).

Apesar deste estudo não ter sido desenhado para pesquisar esta tendência, é possível que a elevação adicional possa ter ocorrido, em parte, devido a retração cicatricial do retalho, além do favorecimento da ação elevadora do músculo frontal sadio após a liberação dos ligamentos retentores do supercílio e unificação dos planos cirúrgicos, mencionados anteriormente. A associação de miotomias e fixação mais rígida, teoricamente possibilitaria maior elevação do supercílio, permitindo o tratamento de ptose acentuada pós PFP. Entretanto o desenho do presente estudo não permite tais conclusões e sugerimos futuras pesquisas com seguimento dos pacientes, a longo prazo, para testar esta hipótese. 


\subsection{Considerações finais}

Em 2005, durante o processo da criação deste projeto de pesquisa, o Ambulatório de Paralisia Facial do Departamento de Otorrinolaringologia do $\mathrm{HC}$ da FMUSP, agregou otorrinolaringologistas ${ }^{7}$ que haviam concluído sua formação em Cirurgia plástica facial - como pós graduação latu senso no departamento de otorrinolaringologia da FMUSP. Dentro de pouco meses, devido a um grande número de pessoas com sequelas de paralisia facial, foi criado o Ambulatório de Plástica para Paralisia Facial - paralelamente ao tradicional Ambulatório de Paralisisa Facial. Os pacientes passaram a ser acompanhados por estes profissionais na área de cirurgia plástica facial, aliado ao atendimento do grupo de otologia, encontrando alívio para sequelas diversas através do Sistema Único de Saúde (SUS).

Durante meu estágio ${ }^{8}$, no Facial Nerve Center no Eye and Ear Infirmary da Universidade de Harvard, em Boston, Massachussets, no ano de 2012, conheci um exemplo internacional bem sucedido, fruto da combinação de otorrinolaringologistas que atuam na área de cirurgia plástica facial e otologia/cirurgia de base de cranêo. Reguardadas as diferenças relativas a tradição da organização e da estrutura assegurada, percebi que, tanto neste serviço quanto em nosso ambulatório da USP, os pacientes podem usufruir de um trabalho dentro de uma mesma equipe, que se especializou no atendimento das diversas necessidades originadas da paralisia facial periférica, contando ainda com o apoio de profissionais da psicologia e fonoaudiologia.

Continuamos a prestar este atendimento multidisciplinar e enfatizamos a importância da ampliaçao do investimento em pesquisa e maior comprometimento das politicas publicas com os direitos humanos, em especial nas areas de saúde e educação, para auxiliar na recuperação, não apenas destes indivíduos com paralisia facial, aliviando seus sintomas e facilitando seu convivio familiar e social, mas de todos os cidadãos.

\footnotetext{
${ }^{7}$ Participaram comigo Sandra Maytê Peres Leon, Carolina Passamani Fagundes e Leila Freire Rego Lima.

${ }^{8}$ Estagiei junto a Dra Tessa Hadlock, professora especializada em Cirurgia Plastica Facial direcionada a Paralisia Facial, acompanhando cirurgias, atendimentos ambulatoriais e reuniões clinico-científicas no primeiro semestre de 2012.
} 
7. CONCLUSÕES 


\section{Conclusões}

1. Concluímos que a frontoplastia não endoscópica, com mínimas incisões, foi eficiente na elevação do supercílio de indivíduos com sequela de paralisia facial periférica, verificado por medidas computadorizadas na linha do canto palpebral lateral da hemiface paralisada, nas fotos pré e 24 meses após a cirurgia.

2. Vinte e quatro meses após a cirurgia, todos os indivíduos responderam estar satisfeitos com a cirurgia e consideraram sua aparência "melhor" ou "muito melhor".

3. Exploratoriamente, observamos que as medidas da posição dos supercílios, 12 meses após a cirurgia, foram superiores em relação ao pré-operatório e esta elevação foi progressiva após 36 a 78 meses. 
8. ANEXOS 


\section{ANEXO A - Protocolo de avaliação de Paralisia Facial Periférica}

GRUPO DE PARALISIA FACIAL - Otorrinolaringologia - Hospital das Clinicas Faculdade de Medicina Universidade de São Paulo - USP, São Paulo.

Etiqueta do paciente:

Raça:

Branca
Negra
Parda
Amarela

Profissão:

Queixa principal:

\section{Paralisia Facial}

Espasmo Facial

Lado: D E

Tempo:

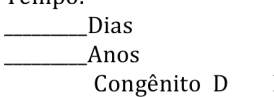

Início:

Súbito

Progressivo

Hipoacusia:

Sim Não
$\begin{aligned} & \text { Zumbido: } \\ & \text { Sim }\end{aligned}$ Não
Vertigem:

Sim Não

Contato com carrapato:

Sim Não

Picado por carrapato: Sim Não

História:

Nega

Feridas no pavilhão

Coma

Cirurgia

Fratura

Etilismo

Edema de face ou lábio

Gravidez

Puerpério

Agenesia de CAE

Diabetes

Hipertensão Arterial

Outros:

Paralisia prévia:
Fator desencadeante:

Nega

Crise hipertensiva

Frio

Neurocirurgia

Mastoidectomia radical

Timpanomastoidectomia

Timpanoplastia

Estapedectomia

Exce. de neurinoma (ORL)

Cirurgia na Parótida

Acidente automobilístico

Acidente moto ciclístico

Atropelamento

Arma branca

Arma de fogo

Otite média aguda

Otite média crônica

Outros:

Antecedentes familiares:

Nega

Paralisia Facial Periférica

Diabetes

Hipertensão

Lupus

Sintomas:

Nega

Dor na hemiface

Dor retroauricular

Otalgia

Cefaléia

Lacrimejamento

Alterações gustativas

Plenitude auricular

Otorréia

Adormecimento da face

Febre

Otorragia

IVAS

Outros:

Exame físico:

Vesículas: Sim Não

Língua plicata: Sim Não Edema da face ou lábio: Sim Não
Otoscopia:

Hemotímpano D E

Perfuração MT D E

Cavidade radical D $\mathrm{E}$

Agenesia CAE D E

Otorréia $\quad \mathrm{D} \quad \mathrm{E}$

Hiperemia D E

Retração MT D E

Colesteatoma D E

Tumor de CAE D E

Tu de ouv. Médio D

OMS

Outros:

Palpação das Parótidas:

Normal

Alteração:

SCORE PS:

data_______ _ _

testa+olhos+sorriso+assobio+tônus

${ }_{-}^{+}{ }^{+}+\ldots+\ldots+\ldots$

SCORE $1^{\text {a }}$ consulta:

$+\ldots+\ldots+\ldots+$

Classificação de House -Brackman:

I Normal

II Disfunção Leve

III Disfunção Moderada

IV Disfunção

Moderada/severa

V Disfunção Severa

VI Paralisia total

Lacrimejamento: Suprageniculado Infrageniculado

Reflexo do Estapédio: Presente

Ausente

Aumentado

Audiometria:

Normal

Neurossensorial:___ dB

Condutiva:__ $\mathrm{dB}$ Gap

Mista VO:

VA: $\quad \mathrm{dB}$

Afecção de outros Pares

Cranianos:

Sim, qual:

Não 
Tomografia

Computadorizada:

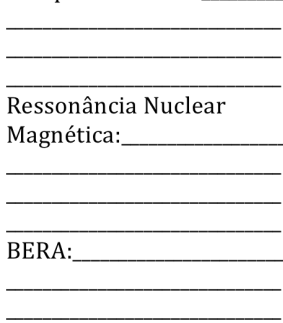

LUES:

Positivo

Negativo

Triglicerídeos:

Colesterol:

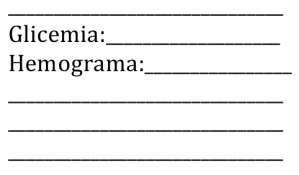

Lyme:

Positivo IgM IgG

Negativo

Eletromiografia:

Potenciais Polifásicos

Potenciais de Fibrilação

Diagnóstico:

Idiopática

Traumática

Doença de Lyme

latrogênica

Metabólica

Tumoral

Ramsay-Hunt

Melkersson Rosenthal

Infecciosa

Congênita

Espasmo Facial Idiopático

Espasmo pós PFP

Espalmo pós galvano

Outro:

Tratamento prévio:

Massagens

Estimulação elétrica

Tratamento clínico:

Cuidados oculares

Corticoide

Carbamazepina

Antiinflamatório

Aciclovir
Encaminhamento:

Terapia Miofuncional

Oftalmologia

Neurologia

Cirurgia Plástica

Outros:

Cirurgia ___ _ _

Transmastoidea

Translabiríntica

Fossa Média

Parótida

Achados cirúgicos:

Fratura

Secção

Espícula óssea

Outros:

Sutura nylon 10.0

Cola de Fibrin

Aproximação dos cotos

Tubulização

Enxerto de Sural

Enxerto Grande Auricular

Descompressão sem abrir

bainha

Descompressão com

bainha

Descrição (localização,

tamanho do

enxerto):

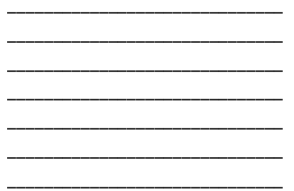

Complicações pós

operatórias:

Cofose

Disacusia neurossensorial

Disacusia condutiva

Vertigem

Zumbido

Fístula Liquorica

Outras:

Observações:
Evolução:

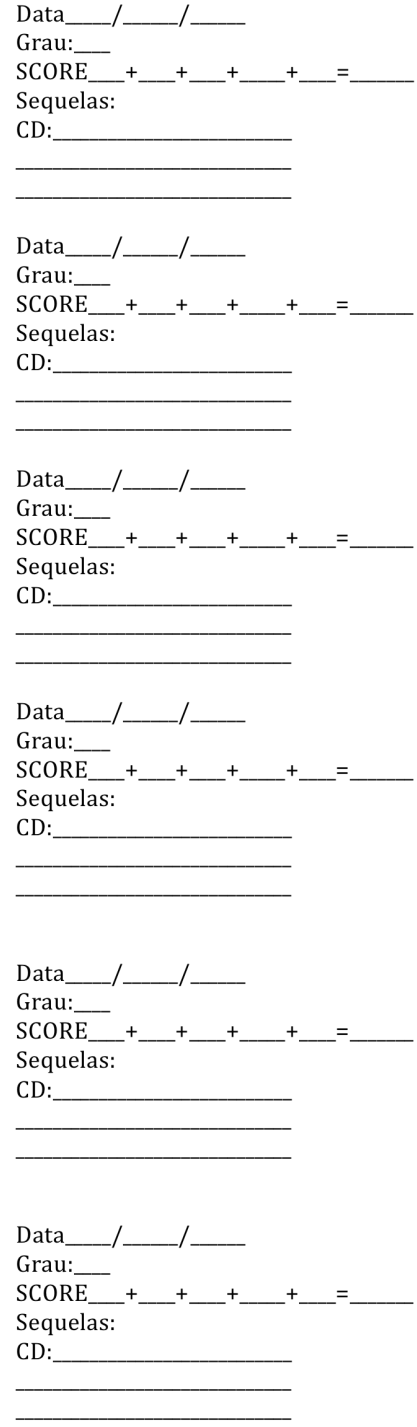




\section{ANEXO B - Escala de House Brackmann ${ }^{9}$}

\begin{tabular}{|c|c|c|c|}
\hline GRAU & DISFUNÇĀO & \multicolumn{2}{|c|}{ CARACTERISTICAS } \\
\hline I & NORMAL & \multicolumn{2}{|c|}{ Função facial normal } \\
\hline ॥ & LEVE & $\begin{array}{l}\text { Leve fraquez } \\
\text { Repouso: } \\
\text { Movimento: }\end{array}$ & $\begin{array}{l}\text { notável a inspeção } \\
\text { Normal, tônus normal } \\
\text { Testa: função quase normal } \\
\text { Olho: fechamento total com mínimo esforço } \\
\text { Boca: assimetria leve }\end{array}$ \\
\hline III & MODERADA & $\begin{array}{l}\text { Diferença lev } \\
\text { Repouso: } \\
\text { Movimento: }\end{array}$ & $\begin{array}{l}\text { porém visivel entre os dois lados } \\
\text { Normal, tônus normal } \\
\text { Testa: alteração moderada } \\
\text { Olho: fechamento total com máximo esforço } \\
\text { Boca: assimetria visível com máximo esforço }\end{array}$ \\
\hline IV & $\begin{array}{l}\text { MODERADAMENTE } \\
\text { SEVERA }\end{array}$ & $\begin{array}{l}\text { Assimetria e } \\
\text { Repouso: } \\
\text { Movimento: }\end{array}$ & $\begin{array}{l}\text { raqueza obvias entre os lados } \\
\text { Normal ou levemente alterado, tônus normal } \\
\text { Testa: ausência de movimento } \\
\text { Olho: fechamento incompleto, presença de fenda } \\
\text { Boca: assimetria importante com máximo esforço }\end{array}$ \\
\hline V & SEVERA & $\begin{array}{l}\text { Movimentos } \\
\text { Repouso: } \\
\text { Movimento: }\end{array}$ & $\begin{array}{l}\text { quase imperceptiveis } \\
\text { Assimetria entre os lados } \\
\text { Testa: ausência de movimento } \\
\text { Olho: fechamento incompleto } \\
\text { Boca: movimento quase imperceptíveis }\end{array}$ \\
\hline$\underline{\mathrm{Vl}}$ & TOTAL & \multicolumn{2}{|c|}{ Ausência total de movimentos. Perda do tônus muscular } \\
\hline
\end{tabular}

${ }^{9}$ Fonte: House JW, Brackmann DE. Facial nerve grading system. Otolaryngol Head Neck Surg. 1985;93(2):146-7. 
ANEXO C - Escala de Sunnybrook ${ }^{10}$

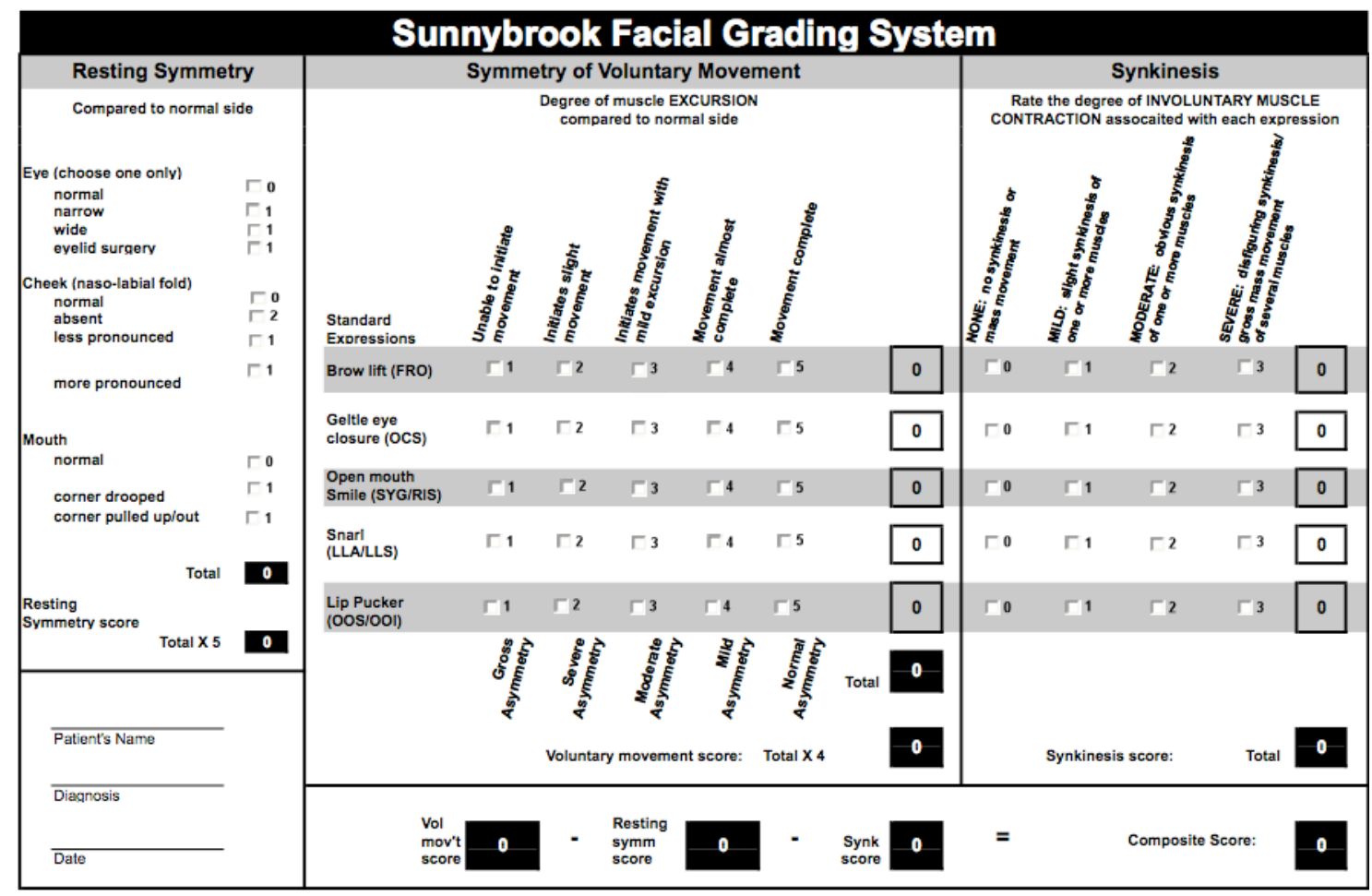

${ }^{10}$ Fonte: Anexos do $12^{\text {th }}$ International Facial Nerve Symposium, Boston Massachusetts, EUA de 28 de junho a 1 de julho de 2013. Diretores: Hadlock TA, Cheney ML, Mckenna M. 
9. REFERÊNCIAS 


\section{REFERÊNCIAS}

Bento RF, Queiroz GMS, Pinna MH. Tratado de Otologia. $2^{\mathrm{a}}$ ed. São Paulo: Atheneu; 2013. p.539-82: Doenças do Nervo Facial.

Burgess LPA, Goode RL. Reanimation of the Paralysed Face. Series: The American Academy of Facial Plastic and Reconstructive Surgery. New York: Thieme Medical Publishers; 1994. p.1: Overview.

Clark JM, Schockley WW. Management and Reanimation of the Paralyzed Face. In: Papel, I. (2 ${ }^{\text {nd }}$ ed) Facial Plastic and Reconstructive Surgery. New York: Thieme Medical Publishers; 2002. p.660-85.

Constantino PD, Hiltzik DH, Moche J, Preminguer A. Minimally Invasive Brow Suspension for Facial Paralisys. Arch Facial Plast Surg. 2003;5:171-4.

da Cruz JRS, Cruz AAV. Quantificação da ação do músculo frontal. Arq Bras Oftalmol. 2004;67(2):237-40.

Dayan SH, Perkins SW, Vartanian AJ, Wiesman IM. The forehead lift: endoscopic versus coronal approaches. Aesthetic Plast Surg. 2001;25(1):35-9.

De Almeida JR, Al Khabori M, Guyatt GH, Witterick IJ, Lin VY, Nedzelski JM, et al. Combined corticosteroid and antiviral treatment for Bell palsy: a systematic review and meta-analysis. JAMA. 2009;302(9):985-93.

De Rossi J, Lima LFR, Fagundes CP. Cirurgia Plástica nas Seqüelas de Paralisia Facial Periférica. In: Tratado de Otorrinolaringologia. $2^{a}$ ed. São Paulo: Roca; 2011. p.720-32.

Domingos MM. O uso da toxina botulínica em doentes com hipercinesia muscular facial contralateral à paralisia facial [tese]. São Paulo: Faculdade de Medicina, Universidade de São Paulo; 2006 [acesso 2012-02-03]. Disponível em: http://www.teses.usp.br/teses/disponiveis/5/5143/tde-17082006-104941/.

Ducic Y, Adelson R. Use of The Endoscopic Forehead-Lift to Improve Brow Position in Persistent Facial Paralysis. Arch Facial Plast Surg. 2005;7:51-54. 
Freeman BS. Review of Long Term Results in Supportive Treatment of Facial Paralysis. Plast Reconst Surg. 1979;63(2):214-18.

Freund RM, Nolan WD. Correlation Between Brow lift Outcomes and Aesthetic Ideal for Eyebrow Height and Shape in Females. Plast Reconst Surg. 1996;97(7):1343-8.

Graham DW, Heller J, Kirkjian TJ, Schaub TS, Rohrich RJ. Brow Lift in Facial Rejuvenation: A Systematic Literature Review of Open versus Endoscopic Techniques. Plast Reconst Surg. 2011;128(4):335-341.

Gullane PJ, Cheng KS. Extratemporal Facial Reanimation. In: Paparella, Shumrick, Gluckman, Meyerhoff. Otolaryngology vol IV-plastic and reconstructive surgery and interrelated disciplines. $3^{\text {rd }}$ ed. USA: WB Saunders Company, 1991.

Gunter JP, Antrobus SD. Aesthetic Analysis of the Eyebrows. Plast Reconst Surg. 1997;99(7):1808-16.

Hadlock T. Facial paralysis: research and future directions. Facial Plast Surg. 2008;24(2):260-7.

Hadlock TA, Greenfield LJ, Wernick-Robinson M, Cheney ML. Multimodality Approach to Management of the Paralysed Face. Laryngoscope. 2006;116:1385-9.

Hoffman WY. Reanimation of the Paralysed Face. Otolaryngol Clin. North Am. 1992;25(3):649-67.

Hydén D, Sandstedt P, Odkvist LM. Prognosis in Bell's Palsy Based on Symptoms, Signs and Laboratory Data. Acta Otolaryngol. 1982;93(5-6):407-14.

Isse NG. Endoscopic Facial Rejuvenation: Endoforhead, the Functional Lift: Case Reports. Aesth Plast Surg. 1994;(18):21-9.

Kennedy BD, Pogue MD. Fixation Techniques for endoscopic brow lift. J Oral Maxillofac Surg. 1999 May;57(5):588-94. 
Kikkawa DO, Miller SR, Batra MK, Lee AC. Small incision nonendoscopic browlift. Ophthal Plast Reconstr Surg. 2000;16(1):28-33.

Knize DM. Limited Incision Forehead Lift for Eyebrow Elevation to Enhance Upper Blepharoplasty Plast Reconstr Surg. 1996;97(7):1334-42.

Knize Dm. Limited Incision Foreheadplasty. Plast Reconstr Surg. 1999;103(1):271-84.

Lemke BN, Stasior OG. The Anatomy of Eyebrow Ptosis. Arch Ophthalmol. 1982;100:981-6.

Machado A. Neuroanatomia Funcional. 2 ed. São Paulo: Atheneu; 2002. p. 119-28.

Marten TJ. Closed, nonendoscopic, small-incision forehead lift. Clin Plast Surg. 2008;35(3):363-78.

Matros E, Garcia JA, Yaremchuk MJ, Changes in Eyebrow position and shape with aging. Plast Reconstr Surg. 2009;124(4):1296-1301.

May M, Levine RE, Patel BCK, Anderson RL. Eye Reanimation Techniques in: The Facial Nerve $2^{\text {nd }}$ ed. New York: Thieme Medical Publishers; 2000. p. 677773.

Meltzer NE, Byrne PJ. Manegement of the Brow in Facial Paralisys. Facial Plast Surg. 2008;24(2):216-9.

Miniti A, Bento RF, Butugan O. Otorrinolaringologia - Clínica e Cirúrgica. $2^{\mathrm{a}}$ ed. São Paulo: Atheneu; 2000.

Monini S, Lazzarino Al, lacolucci C, Buffoni A, Barbara M. Epidemiology of Bell's palsy in an Italian health district: Incidence and case-control study. Acta Otorhinolaryngol Ital. 2010;30(4):198.

Moody FP, Losken A, Bostwick J, Trinei FA, Eaves FF. Endoscopic Frontal Branch Neurectomy, Corrugator Myectomy, and Brow lift for Forehead Asymmetry after Facial Nerve Palsy. Plast Reconstr Surg. 2001 July;108(1):218-24. 
Parnes S, Batniji R. Facial reanimation. In: Bailey BJ, Johnson JT editors. Head and neck surgery: otolaryngology $3^{\text {rd }}$ ed. Philadelphia: Lippincott Williams and Wilkins; 2001. p.2467-80.

Peitersen E. Bell's Palsy: the spontaneous course of 2,500 peripheral facial nerve palsies of different etiologies. Acta Otolaryngol Suppl. 2002;(549):4-30.

Ramirez O. Endoscopic Technique in Facial Rejuvenation: An Overview. Part I. Plast Reconstr Surg. 1994;18:141-7.

Rautio J, Pignatti M. Endoscopic forehead lift for ptosis of the brow caused by facial paralysis. Scand J Plast Reconstr Hand Surg. 2001;35:51-6.

Ross BG, Fradet G, Nedzelski JM. Development of a sensitive clinical facial grading system. Otolaryngol Head Neck Surg. 1996;114(3):380-6.

Rubin LR. Reanimation of the Paralysed Eyelid. In: The Paralysed Face. St. Louis: Mosby - Year Book; 1991. p. 234-42.

Sadr J, Jarudi I, Sinha P. The role of eyebrows in face recognition. Perception 2003;32(3):285-93.

Salomone R in: Bento RF, Voegels de RL, Sennes LU, Pinna FR, Jotz GP Otorrinolaringologia Baseada em Sinais e Sintomas. São Paulo: Fundação Otorrinolaringologia; 2011, v1 p. 55-56.

Seify H, Jones G, Bostwick J, Hester R. Endoscopic-Assisted Face Lift. Review of 200 cases. Ann Plast Surg. 2004;52:234-9.

Sobol SM, May M. Hypoglossal-Facial Anastomosis: Its Role in Contemporary Facial Reanimation. In: Rubin LR. The Paralysed Face. St. Louis: Mosby - Year Book; 1991. p.137-43.

Stennert E. Why Does The Frontalis Muscle "Never Come Back"? Functional Organization of the Mimic Musculature. Eur Arch Otorhinolaryngol, 1994;(Suppl):S91-S95.

Tabatabai N, Spinelli HM. Limited Incision Nonendoscopic Brow Lift. Plast Reconst Surg. 2007;119(5):1563-70. 
Takushima A, Harii K, Sugawara YA, Sato H. Anthropometric measurments of eyebrow lift in the treatment of facial paralysis. Plast Reconst Surg. 2003; $111(7): 2157-65$.

Troilius C. A Comparison between Subgaleal and Subperiosteal Brow Lifts. Plast Reconstr Surg. 1999;04:1079-90.

Troilius C. Subperiosteal brow lifts without fixation. Plast Reconstr Surg. 2004;114(6):1595-1603.

Ueda K, Harii K, Yamada A. Long-term Follow-up Study of Browlift for Treatment of Facial Paralysis. Ann Plast Surg. 1994 Feb;32(2):166-170.

Ushio M, Kondo K, Takeuchi N, Tojima H, Yamaguchi T, Kaga K. Prediction of the prognosis of Bell's palsy using multivariate analyses. Otol Neurotol. 2008;29(1):69-72.

Yamamoto Y, Sasaki S, Furukawa H, Oyama A, Endo N, Sugihara T, Furuta Y. Anchoring Correction of Eyebrow Ptosis in Facial Palsy. Plast Reconst Surg. 2001 Oct;108(5):1297-9.

Whitaker LA, Morales L, Farkas LG. Aesthetic Surgery of the Supraorbital Ridge and Forehead Structures. Plast Reconst Surg. 1986;78(1):23-32. 
10. APÊNDICES 
Apêndice 1 - Aprovação do projeto de pesquisa pelo comitê de ética

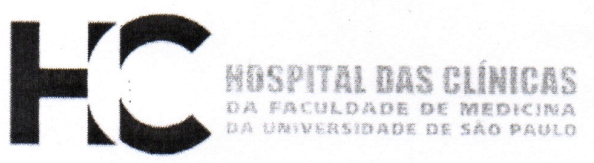

\section{APROVACÃO}

A Comissão de Ética para Análise de Projetos de Pesquisa - CAPPesq da Diretoria Clínica do Hospital das Clínicas e da Faculdade de Medicina da Universidade de São Paulo, em sessão de 09.11.05, APROVOU o Protocolo de Pesquisa $n^{\circ}$ 933/05, intitulado: "Avaliação do ganho de elevação dos supercílios pós paralisia facial periférica, em pacientes submetidos a frontoplastia endoscópica" apresentado pelo Departamento de OFTALMOLOGIA E OTORRINOLARINGOLOGIA, inclusive o Termo de Consentimento Livre e Esclarecido.

Cabe ao pesquisador elaborar e apresentar à CAPPesq, os relatórios parciais e final sobre a pesquisa (Resolução do Conselho Nacional de Saúde n 196, de 10.10.1996, inciso IX. 2, letra "c")

Pesquisador(a) Responsável: Prof. Dr. Silvio Antonio Monteiro Marone Pesquisador (a) Executante: Dra. Janaina de Rossi

CAPPesq, 09 de Novembro de 2005.

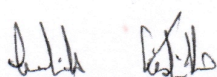

PROF. DR. EUCLIDES AYRES DE CASTILHO Presidente da Comissão de Ética para Análise de Projetos de Pesquisa

Comissão de Ética para Análise de Projetos de Pesquisa do HCFMUSP e da FMUSP Diretoria Clínica do Hospital das Clínicas da Faculdade de Medicina da Universidade de São Paulo Rua Ovídio Pires de Campos. 225, $5^{\circ}$ andar - CEP 05430010 - São Paulo - SP

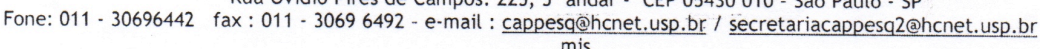


Apêndice 1 - Aprovação de alterações do projeto de pesquisa pelo comitê de ética

\section{APROVAÇÃO}

A Comissão de Ética para Análise de Projetos de Pesquisa - CAPPesa da Diretoria Clínica do Hospital das Clínicas da Faculdade de Medicina da Universidade de São Paulo, em sessão de 16/03/2011, APROVou as alteraçōes abaixo mencionado(s) no Protocolo de Pesquisa $n^{\circ}$ 0933/05, intitulado: "Avaliação do ganho de elevação dos supercílios pós Paralisia Facial Perférica, em pacientes submetidos a frontoplastia Endoscópica "apresentado pelo Departamento de Oftalmologia e Otorrinolaringologia.

Carta datada de 31/01/11:

- Adendo ao protocolo.

- Novo Termo de Consentimento Livre e Esclarecido.

- Troca do pesquisador responsável de Silvio Antonio Monteiro Marone para Ricardo Ferreira Bento

- Mudança de titulo para: "Frontoplastia com mínimas incisōes para elevação do supercílio em portadores de paralisia facial periférica"

Comentários do relator(a) : "Trata-se de protocolo de pesquisa anteriormente aprovado sob o título "Avaliação do Ganho de elevação dos supercílios pós paralisia facial periférica em pacientes submetidos a frontoplasia endoscópica", sob responsabilidade do Prof. Dr. Silvio Antonio Monteiro Marone. Em carta de 31 de janeiro de 2011, esta equipe requer a substituição do pesquisador responsável, para que figure nessa posição o Dr. Ricardo Ferreira Bento, assim como reapresenta projeto de pesquisa, alegando que os grupos de pacientes anteriormente descritos, respectivamente acometidos ou não de paralisia do músculo frontal foram operados, mas notaram que o grupo de pacientes sem paralisia não necessita ser operado para atingir o objetivo do estudo. Pretendem realizar comparação entre o lado saudável e o lado paralisado do mesmo paciente e perceberam a desnecessidade do uso do endoscópio no procedimento adotado, apontando, inclusive, referências bibliográficas. O TCLE é adequado e o projeto atende satisfatoriamente as exigências metodológicas. Opino pela aprovação do novo protocolo."

Pesquisador (a) Responsável: Ricardo Ferreira Bento

Pesquisador (a) Executante: Janaina de Rossi

CAPPesq, 16 de março de 2011

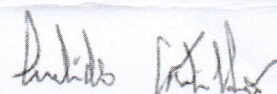

PROF. DR. EUCLIDES AYRES DE CASTILHO

Coordenador

Comissão de Ética para Análise de

Projetos de Pesquisa - CAPPesq

Comissão de Ética para Análise de Projetos de Pesquisa do HCFMUSP da Diretoria Clínica do Hospital das Clinicas da Faculdade de Medicina da Universidade de São Paulo Rua Ovídio Pires de Campos, 225, $5^{\circ}$ andar - CEP 05403010 - São Paulo - SP Fone: 01130696442 Fax: 01130696492 e-mail: 